\title{
Center of Excellence Collaboration Projects: Second Wave
}

Nuclear Science and Engineering Division 


\begin{abstract}
About Argonne National Laboratory
Argonne is a U.S. Department of Energy laboratory managed by UChicago Argonne, LLC

under contract DE-AC02-06CH11357. The Laboratory's main facility is outside Chicago, at

9700 South Cass Avenue, Argonne, Illinois 60439. For information about Argonne

and its pioneering science and technology programs, see www.anl.gov.
\end{abstract}

\title{
DOCUMENT AVAILABILITY
}

Online Access: U.S. Department of Energy (DOE) reports produced after 1991 and a growing number of pre-1991 documents are available free at OSTI.GOV

(http://www.osti.gov/), a service of the US Dept. of Energy's Office of Scientific and

Technical Information.

Reports not in digital format may be purchased by the public from the

National Technical Information Service (NTIS):

U.S. Department of Commerce

National Technical Information Service

5301 Shawnee Rd

Alexandria, VA 22312

www.ntis.gov

Phone: (800) 553-NTIS (6847) or (703) 605-6000

Fax: (703) 605-6900

Email: orders@ntis.gov

\author{
Reports not in digital format are available to DOE and DOE contractors from the \\ Office of Scientific and Technical Information (OSTI): \\ U.S. Department of Energy \\ Office of Scientific and Technical Information \\ P.O. Box 62 \\ Oak Ridge, TN 37831-0062 \\ www.osti.gov \\ Phone: (865) 576-8401 \\ Fax: (865) 576-5728 \\ Email: reports@osti.gov
}

\section{Disclaimer}

This report was prepared as an account of work sponsored by an agency of the United States Government. Neither the United States Government nor any agency thereof, nor UChicago Argonne, LLC, nor any of their employees or officers, makes any warranty, express or implied, or assumes any legal liability or responsibility for the accuracy, completeness, or usefulness of any information, apparatus, product, or process disclosed, or represents that its use would not infringe privately owned rights. Reference herein to any specific commercial product, process, or service by trade name, trademark, manufacturer, or otherwise, does not necessarily constitute or imply its endorsement, recommendation, or favoring by the United States Government or any agency thereof. The views and opinions of document authors expressed herein do not necessarily state or reflect those of the United States Government or any agency thereof, Argonne National Laboratory, or UChicago Argonne, LLC. 


\section{Center of Excellence Collaboration Projects: Second Wave}

J. Fang, L. Brockmeyer, G. Hu, L. Zou, R. Hu, E. Merzari Nuclear Science and Engineering Division,

Argonne National Laboratory

K. Karazis

Framatome

June $30^{\text {th }}, 2020$ 


\section{SUMMARY}

The NEAMS program aims to develop an integrated multi-physics simulation capability "pelletto-plant" for the design and analysis of future generations of nuclear power plants. In particular, the Reactor Product Line code suite's multi-resolution hierarchy is being designed to ultimately span the full range of length and time scales present in relevant reactor design and safety analyses, as well as scale from desktop to petaflop computing platforms. In particular the NEAMS program is supporting the development of novel thermal-hydraulic codes.

The Center of Excellence for Thermal Fluids Application in Nuclear Energy, launched in 2018, has as its key goals to serve as a front door to industry. The Center of Excellence for Thermal Fluids Applications in Nuclear Energy has recently launched a program to start collaborative efforts between the laboratories and industry with the objective of stimulating cooperation and increasing adoption of T/H tools developed under NEAMS by the industry-at-large.

In particular, two industry partners agreed to participate in a second wave of short-term collaborations aimed at demonstrating the value of NEAMS tools to their designs. These are Framatome and TerraPower who proposed projects related to LWR (Light Water Reactor) and MSFR (Molten Salt Fast Reactor) designs respectively. In this report we present the results of these two collaborations. 


\section{CONTENTS}

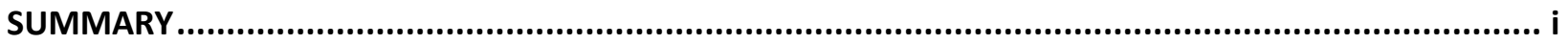

1 Introduction

2 Framatome project: Effect of Localized Cross-Flow on the Stability of Peripheral LWR Fuel Rods ......4

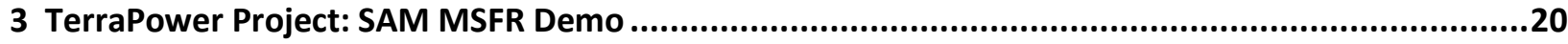

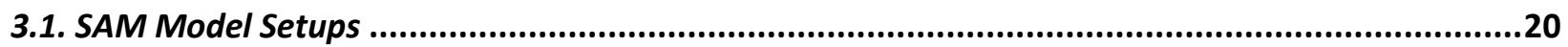

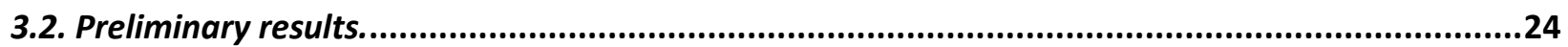

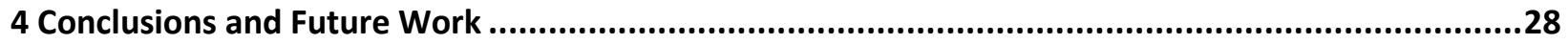

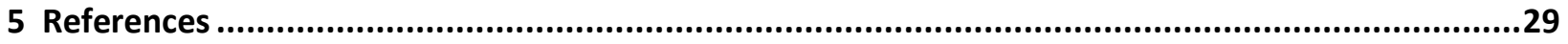




\section{Introduction}

The Center of Excellence for Thermal Fluids Applications in Nuclear Energy has recently launched a program to start collaborative efforts between the laboratories and industry with the objective of stimulating cooperation and increasing adoption of $\mathrm{T} / \mathrm{H}$ tools developed under NEAMS by the industry-at-large.

In December 2019 the center held a meeting focused on collaboration with industry. The collaboration program was launched at the meeting. Moreover, two industry partners agreed to participate in pilot short-term collaborations aimed at demonstrating the value of NEAMS tools to their designs. These are Framatome and TerraPower who proposed projects related to LWR (Light Water Reactor) and MSFR (Molten Salt Fast Reactor) designs respectively.

The diagram below aims to illustrate the role of these short-term projects. The feedback from industry has been overwhelmingly positive. We note that these short term projects are not aimed at providing a funding venue and they are not aimed at providing a means to address problems that require protection of IP. That need is served by Gateway for Advanced Innovation in Nuclear (GAIN) vouchers. Rather, these short term projects are aimed at fulfilling the role of the center as a "front-door" to industry. They can be used by industry to propose short term activities aimed at demonstrating the tools in preparation for larger proposals. The potential paths of industrial customers are illustrated in the diagram below reflecting different levels of commitment from the industry partner.

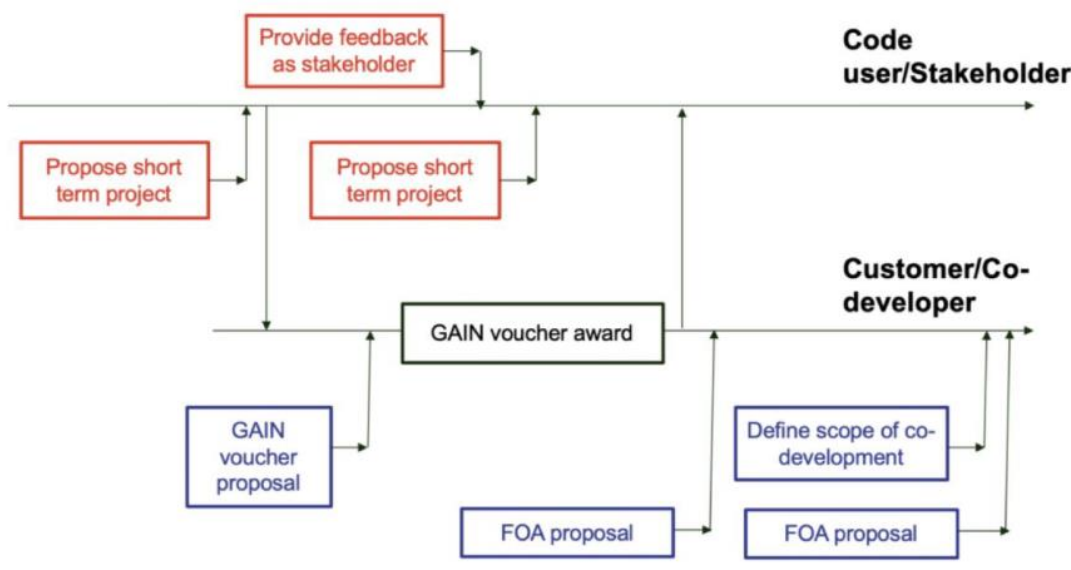

Fig. 1. Potential paths for industry collaboration in the center.

Once short term projects are completed, industry partners can propose additional work under the GAIN program working with our lab team members. This can also lead to additional funding opportunities through a funding opportunity announcement (FOA) proposal and eventually lead to co- development of codes or projects. Alternatively, the industry partner can choose to remain less involved, through repeated short-term proposals and as a stake-holder. In the following sections the results of the second wave of pilot projects with Framatome, concerning the analysis of the 
flow field around LOCA holes, and TerraPower, concerning the creation of a demo SAM MSFR model.

\section{Framatome project: Effect of Localized Cross-Flow on the Stability of Peripheral LWR Fuel Rods}

Fuel rods in PWRs are exposed to severe thermal, mechanical and irradiation loads during operation. The mechanical forces from cooling are primarily from axial flow, which poses relatively low risk for destructive vibrations. However, some core geometries experience local jets of transverse flow, either by design or due to wear. Crossflow introduces a much greater risk for the onset of destructive vibrations. To better understand the interaction between local jet flow and bulk axial flow in a rod bundle, four permutations of this domain were simulated. The position of the jet, gap-centered vs. rod-centered, and angle of the jet, perpendicular vs. 45-degree angle, were varied. The transverse flow at several axial slices was examined along with an analysis of the pressure exerted on rods near the jet. The jet quickly creates a highly fluctuating transverse flow around the nearby pins. Behind the jet forms a low-pressure region, sometimes inducing local flow reversal. As the jet dissipates, transverse flow circulates around the jet to fill the low-pressure region. The perpendicular jets cause dramatically more disruption, propagating for $10 \mathrm{~s}$ of $\mathrm{cms}$. The gap-centered jets result in a larger area of transverse flow affecting more pins, while the rodcentered jets result in greater pressure loads on the nearby pins.

\subsection{Introduction}

The fuel rods in a PWR plant are subjected to primarily external axial flow. However, at certain locations along the span, a transverse flow component is also present near the LOCA holes [1]. LOCA holes or slots (elliptical shape) are present by design in the Babcock and Wilcox PWR reactors that are still in service today. Other older reactors are susceptible to slot development at the seam of two different baffle plates because of thermal and pressure differentials (internal vs external) as a direct effect of faulty baffle bolts [2]. Fuel rods subjected to crossflow are susceptible to much higher vibration levels than in purely axial flow. In extreme cases, the fuel rods may undergo (intermittent) fluidelastic instability - resulting in violent and destructive vibrations. Flow periodicities, induced by shear layer oscillations and vortex shedding, may also potentially cause strong resonance oscillations. Single flexible tubes undergo instability via the 1-dof negative damping mechanisms; this mechanism has only been found for flexibility transverse to the flow direction. Cross-coupling between neighboring tubes can also lead to instability via the stiffness controlled mechanism [3]. All these undesirable instabilities are responsible for grid-to-rodfretting (GTRF) and wear of the fuel rod cladding.

Unlike the case of axial-flow turbulence excitation, little fundamental work has been done on crossflow jet induced vibrations in fuel bundles. The current project addressed the fundamental problem of rod bundles subjected to combined axial and jet-flow in the transverse direction by performing a high-fidelity computational fluid dynamics (CFD) study of a reduced bundle geometry. A single span simplified geometry - no grids were used in the simulation - is used in the CFD analysis. The resulting hydraulic loads acting on the fuel rods will be used by Framatome to analyze the stability of the fuel rod near by the LOCA hole. The effect of structural nonlinearities will be taken into account by the in-house structural solver developed at Framatome. The final goal of this collaboration is the stability analysis of fuel rods subjected to axial and transverse flow 
components. Analysis of the flow patterns and dynamics near the LOCA holes will also be of interest for thermal-hydraulic assessments.

The results from this collaborative project will be evaluated against existing experimental datasets and numerical results. The experimental results for jet flow instabilities are scarce and only few have addressed jet-flow-induced FEI. Framatome has performed a number of tests of reduced scale and full scale fuel bundles subjected to LOCA hole jet flow [4]. A number of experiments and numerical simulations have been performed by Fujita et al. [5] and Fujita [6]. The final assessment of the current work will be performed by Framatome comparing the fuel rod stability due to LOCA hole hydraulic loads against recent tests performed at the PETER loop facility.

\subsection{Methodology}

Large-eddy simulation is a technique for numerically simulating turbulent fluid flow by directly solving the motion of the fluid while modeling the smallest scales of motion. The baseline assumption is that the dissipative scales of motion, the smallest scales, behave isotropically, i.e. the Kolmogorov's hypothesis of local isotropy. By modeling these scales, LES reduces the mesh resolution and time resolution requirements of directly simulating the fluid flow, thereby significantly reducing computational cost. Lower-fidelity turbulent simulation methods such as Reynolds-averaged Navier-Stokes (RANS) and unsteady-RANS reduce the computational cost even further but have not been demonstrated to capture the fluctuating eddies and pressure field to the degree necessary to predict the forces imparted on the rods. LES is selected for the present case for its ability to resolve the flow-phenomena resulting from cross-flow at a reasonable computational cost.

The LES calculations are carried out using Nek5000. Nek5000 is a primarily LES/DNS CFD code developed at Argonne National Laboratory. Nek5000 uses the spectral element method, a high order variant of the finite element method. The mesh is composed of curvilinear hexahedral elements much like a finite element mesh might be. The solution within the elements, however, is described by nth order polynomials with $(n+1)^{3}$ collocation points distributed according to the Gauss-Lobatto quadrature. The advantage of the high order formulation is that the convergence is exponential in $n$, meaning that fewer gridpoints are required to resolve smaller wavelengths, which are implicitly present in turbulent and transitioning flow. The lower mesh count requires fewer computational resources, and allows for larger timestepping, compounding into a large improvement in scaling and efficiency. The present study uses $7^{\text {th }}$ order polynomials, meaning each element is described by an 8x8x8 array of gridpoints. Nek5000 has been demonstrated to capture crossflow through a tube bundle fluid only and coupled to a structure code by Brockmeyer [7].

When performing LES, Nek5000 models the dissipation at subgrid scales using a low-pass filter method, essentially acting as a hyper-viscosity. At each timestep a specified percentage of energy is directly removed from a specified number of the highest frequency modes of each element. The filtering method is described in greater detail by Fischer [8]. In the present case 15\% of the energy is removed from the highest mode each time step.

The present study concerns four permutations of a crossflow jet impinging on axial flow in a rod bundle. The characteristic measurements of the bundles are listed in Table 1. Two cases concern bundles such that the impinging jet is centered on a gap between two rows. These two cases consist 
of 8 rows and 7 columns, where the jet impinges between rows 4 and 5 . In one case the jet impinges perpendicular to the bulk flow; in the second case the jet impinges at a 45 degree angle with the bulk flow. These gap-centered cases are referred to as GC_0 and GC_45 respectively. The remaining two cases concern bundles such that the impinging jet is centered on a row. These two cases consist of 9 rows and 7 columns, where the jet impinges on row 5. Like the gap-centered cases, in one case the jet flow in perpendicular to the bulk flow, and in the other case the jet impinges at a 45 degree angle with the bulk flow. These two rod centered cases are referred to as $\mathrm{RC} \_0$ and $\mathrm{RC} \_45$. For each case, a pipe leads to the jet hole in order to have a more realistic jet profile entering the bundle region. The full domain for GC_0 is shown in Fig. 2.

Table 1. Key dimensions

\begin{tabular}{|l|l|}
\hline Dimension & Length $(\mathrm{cm})$ \\
\hline Rod Diameter (D) & 1.092 \\
\hline Rod Pitch $(\mathrm{P})$ & 1.443 \\
\hline Hole Diameter $\left(\mathrm{D}_{\mathrm{H}}\right)$ & 3.50 \\
\hline Simulation Length $(\mathrm{L})$ & 40.0 \\
\hline Hole Z Position $\left(\mathrm{L}_{\mathrm{H}}\right)$ & 10 \\
\hline Recycling Length $\left(\mathrm{L}_{\mathrm{R}}\right)$ & 4.0 \\
\hline Jet Pipe Length $\left(\mathrm{L}_{\mathrm{P}}\right)$ & 10.0 \\
\hline Wall Gap $(\mathrm{G})$ & 0.465 \\
\hline
\end{tabular}

The inlet boundary condition is recycling with a length of $4 \mathrm{~cm}$. The recycling boundary condition maintains a constant average axial velocity of $5.2 \mathrm{~m} / \mathrm{s}$. The inlet of the pipe is a steady hyperbolic velocity profile with a mean velocity of $3 \mathrm{~m} / \mathrm{s}$. The profile is described by equation 1 , where $U$ is the velocity magnitude, and $r$ is the radius from the center. The profile is scaled to the mean velocity. The outlet boundary condition enforces $\operatorname{div} \mathrm{U}<0$ to prevent backflow. The $\mathrm{Y}$ - and $\mathrm{Y}+$ sides of the domain (i.e. the sides adjacent to the inlet hole side) are periodic boundary conditions. The X-side (i.e. the side with the hole) is a wall. The $\mathrm{X}+$ side, opposite the jet hole, maintains a symmetric boundary condition. The sides of the rods and the outside of the jet pipe are walls. The fluid is water at $40^{\circ} \mathrm{C}$.

$$
U(r)=1.0+1.33 f^{0.5}+2 f^{0.5} \log \left(\frac{\frac{D_{H}}{2}-r}{\frac{D_{H}}{2}}\right)
$$



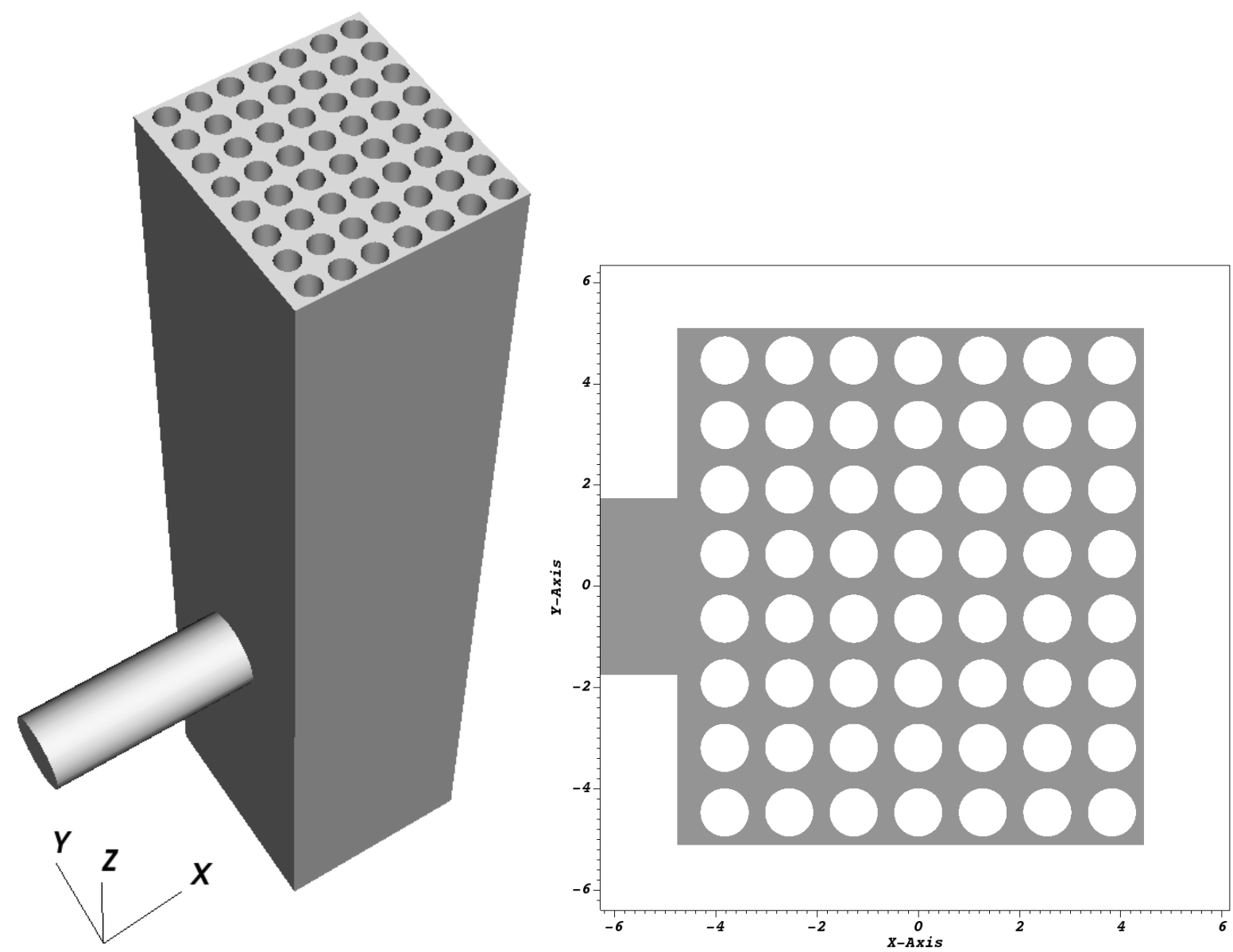

Figure 2. Domain of GC_0: Left: 3D domain, Right: Perpendicular cross-section at center of impinging jet.

The bare-rod bundle is a relatively simple geometry in terms of mesh given its periodic nature and lack of intricate details. The present cases are only complicated by the presence of a round jet impinging on one side of the bundle. The meshing process for each case is identical: create a 2D mesh of the bundle cross section and extrude it to 3D. The area connecting the jet tube to the bundle is meshed by hand to create a circular inlet. Mesh generation was accomplished using the open-source meshing tool Gmsh [9], and the Nek5000 conversion tool gmsh2nek. Cross sections of the mesh for GC_0 are shown in Figure 3; the meshes show the elements without the spectral discretization. The tube connecting meshes for GC and RC cases are different, and both are shown in Fig. 4. The mesh contains a thin element at the walls to resolve the boundary layer. The y+ value at the wall is $>2$ for $60 \%$ of elements, and $<5$ for $99.5 \%$. 

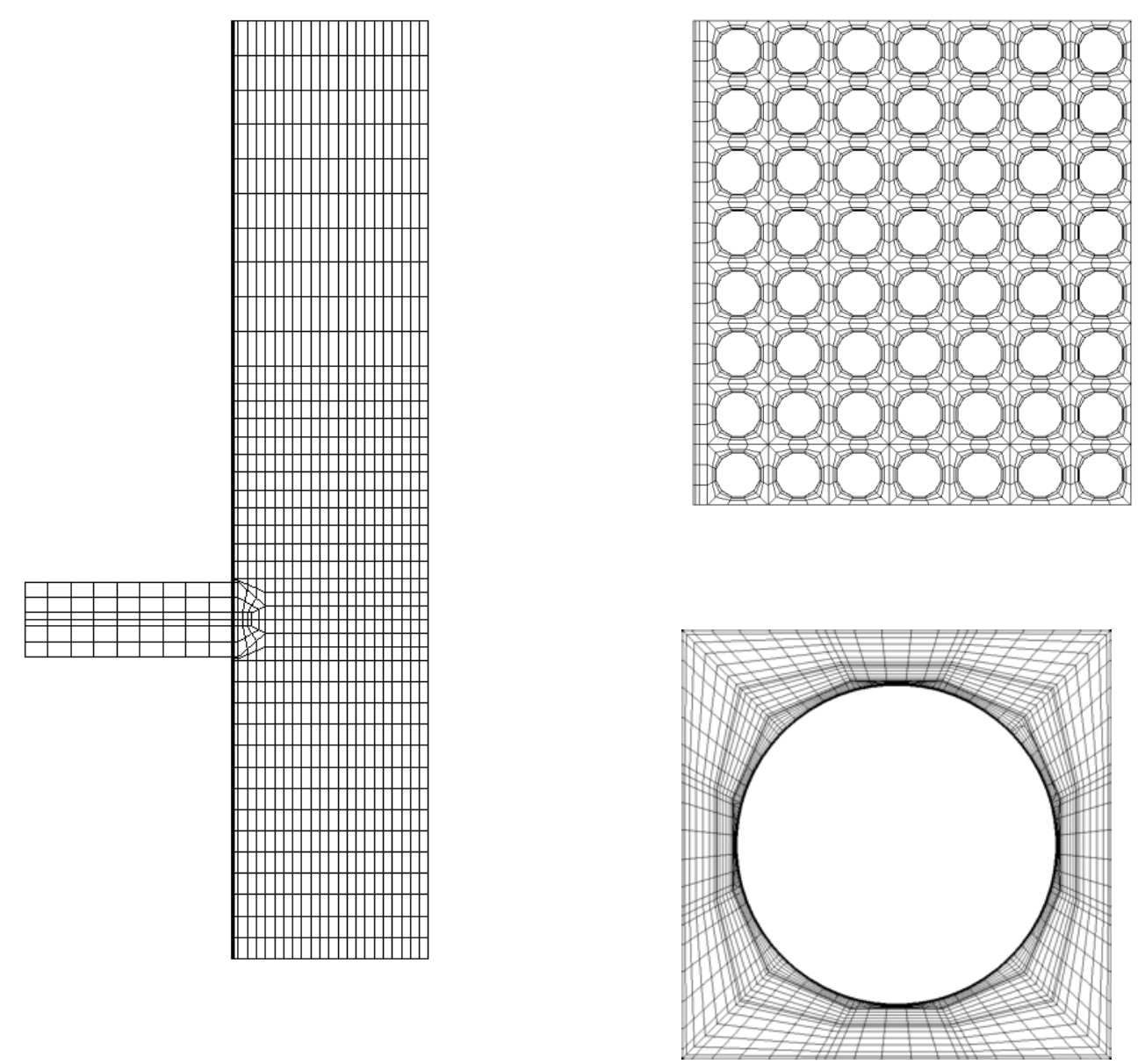

Figure 3. Left: Vertical cross section of element mesh. Top-right: Horizontal cross section of element mesh. Bottom-right: Spectral element mesh around a single rod with polynomial order 7.

\subsection{Results}

Each of the four cases are observed from two perspectives. First, axial slices of the flow are observed at various $\mathrm{z}$ locations above and below the jet. The mean transverse velocity field is displayed. Line plots of the mean transverse velocity and standard deviation on the planes are shown at various distances from the jet. This perspective illustrates the impact of the jet, specifically the crossflow induced around the rods. The second perspective is an analysis of the pressures imparted on the rods. Both the magnitude and spectrum of the pressure are analyzed for several rods near the jet. The magnitude and the power spectrum of the pressure exerted on the fuel rods are important regarding flow induced vibrations. 

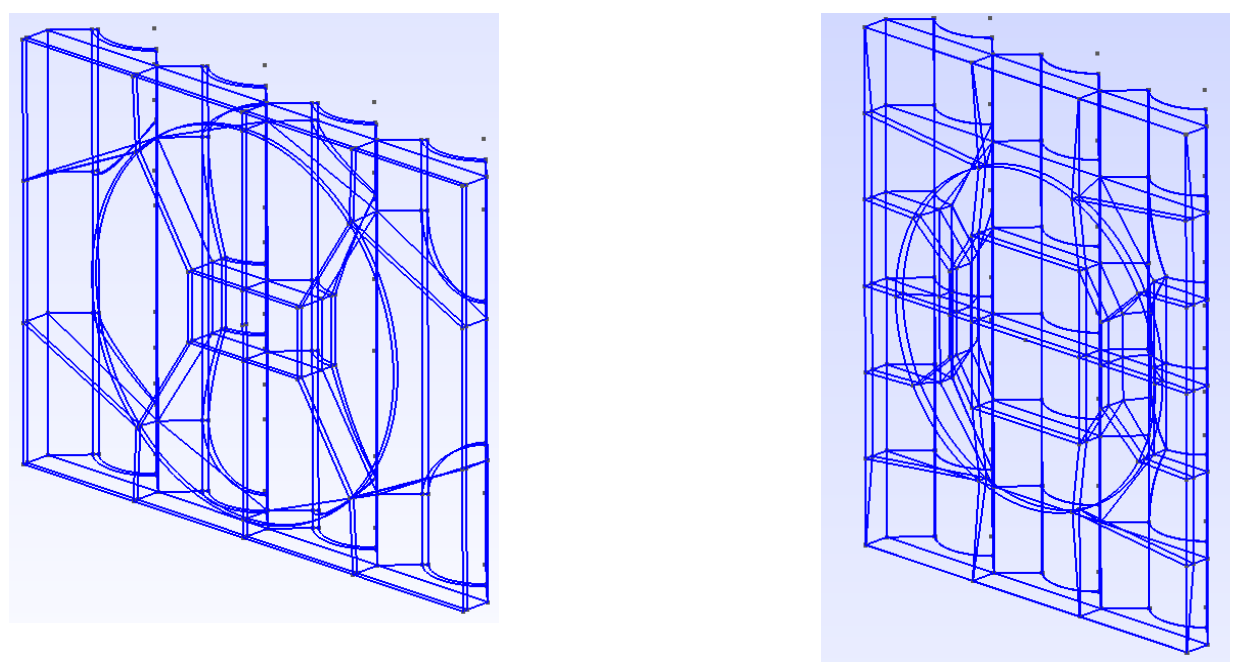

Figure 4. Meshes connecting the circular inlet to the otherwise regular rod bundle. Left: Mesh for gap-centered jet (GC), Right: Mesh for rod-centered jet (RC).

Five planes have been selected to observe the transverse flow for each of the four cases. One plane below the jet is mostly undisturbed and shows the bare bundle behavior. One plane is at the center of the jet, where peak velocities are likely found. The remaining 3 planes are distributed above the jet. These three planes help demonstrate which rods are most impacted and how the jet develops and dissipates upstream. Table 2 lists the axial slice $\mathrm{z}$ values and their position relative to the center of the impinging jet. Figures 5-8 show the 5 transverse flow fields, and two line-plots of transverse flow within each field, including standard deviation.

Table 2. List of axial slices for analysis, corresponding to figures 5:8.

\begin{tabular}{|l|l|}
\hline Plane $\mathrm{Z}(\mathrm{cm})$ & Position relative to jet $(\mathrm{cm})$ \\
\hline 6.0 & -4.0 \\
\hline 10.0 & 0.0 \\
\hline 13.5 & 3.5 \\
\hline 17.0 & 7.0 \\
\hline 25.5 & 15.5 \\
\hline
\end{tabular}



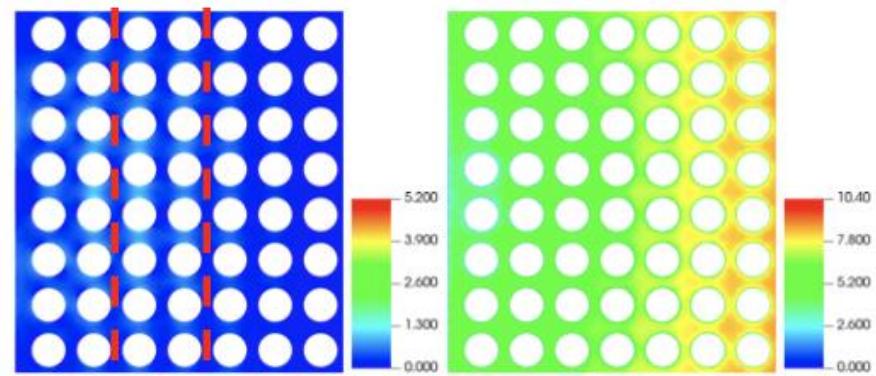

$\mathrm{Z}=6 \mathrm{~cm}$
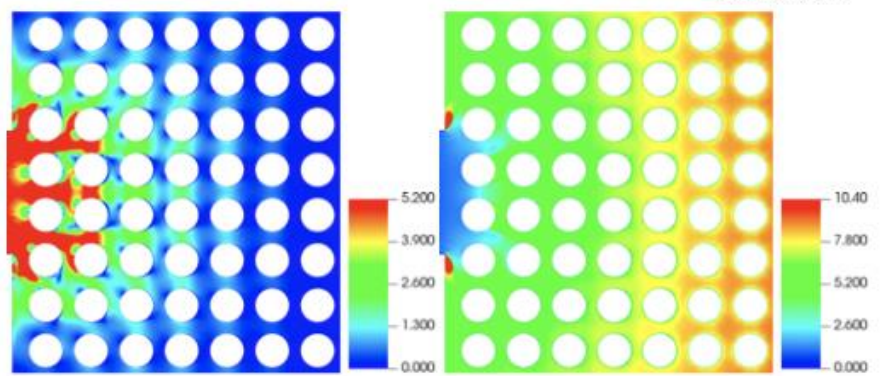

$Z=10 \mathrm{~cm}$ (center of jet)
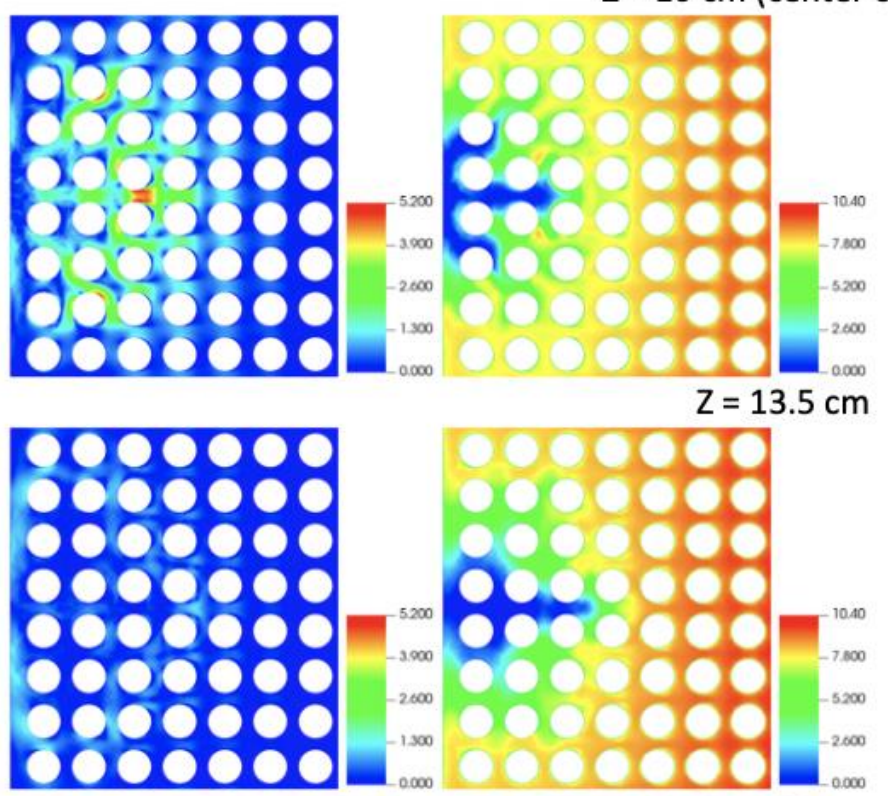

$\mathrm{Z}=17 \mathrm{~cm}$
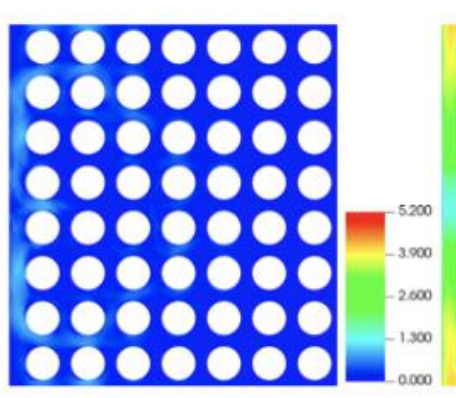
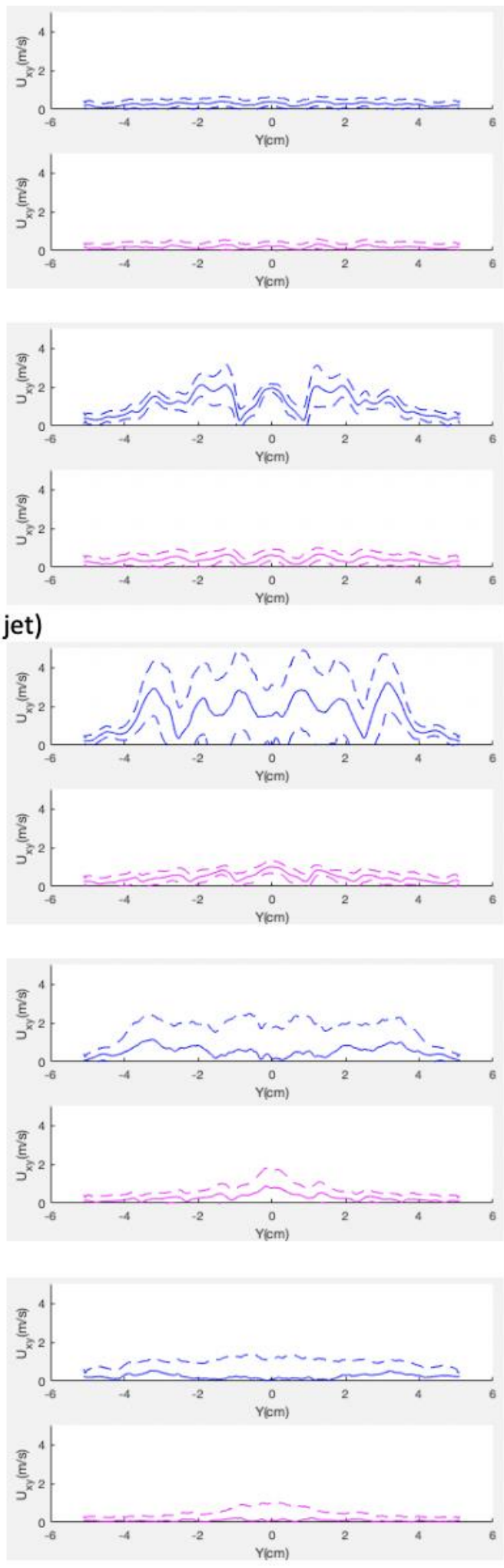

Figure 5. GC_0. Left: Transverse and streamwise velocity fields (m/s) on horizontal slices. Right: Line-plots of transverse velocity with std dev. Location shown on top left image. 

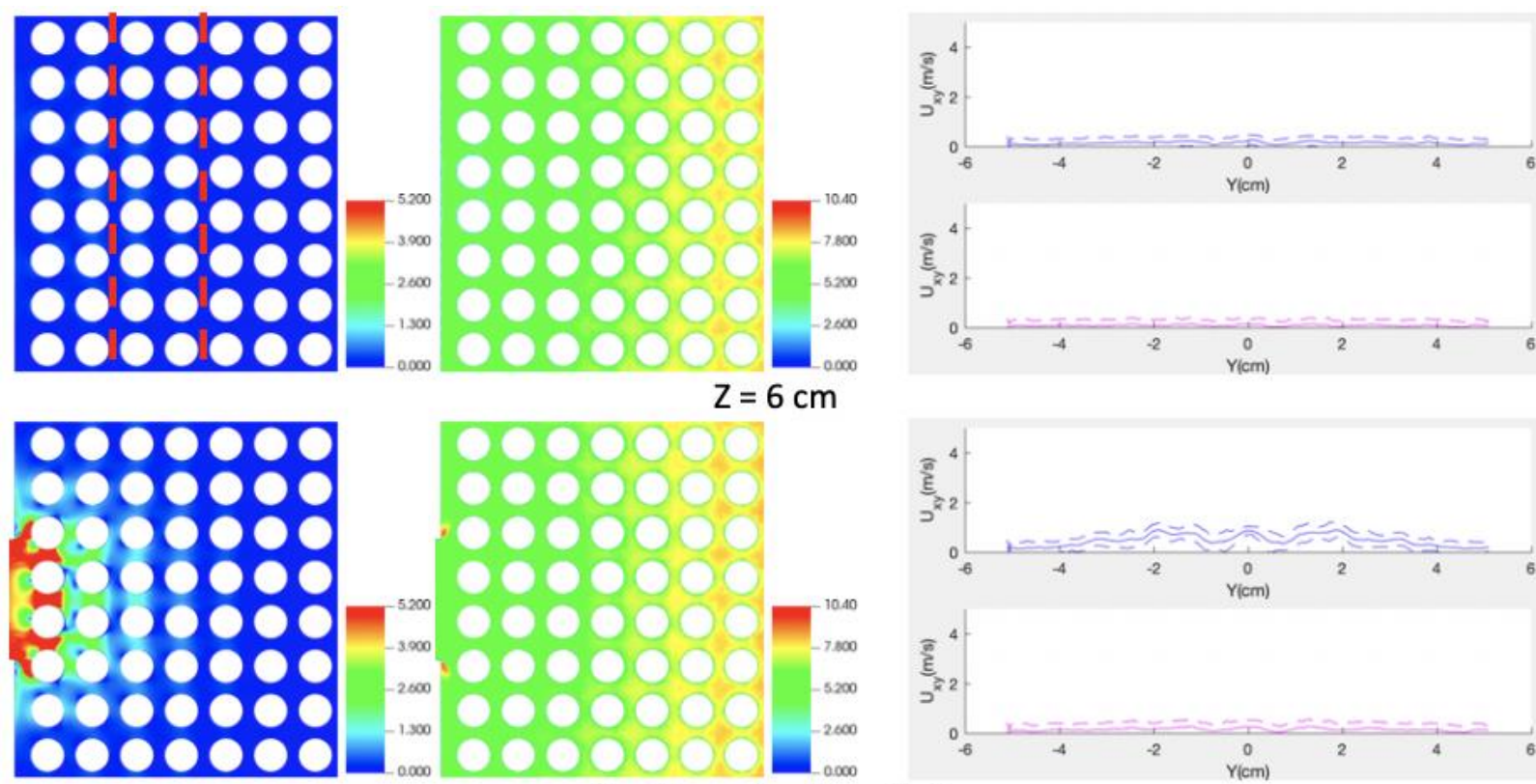

$$
Z=6 \mathrm{~cm}
$$
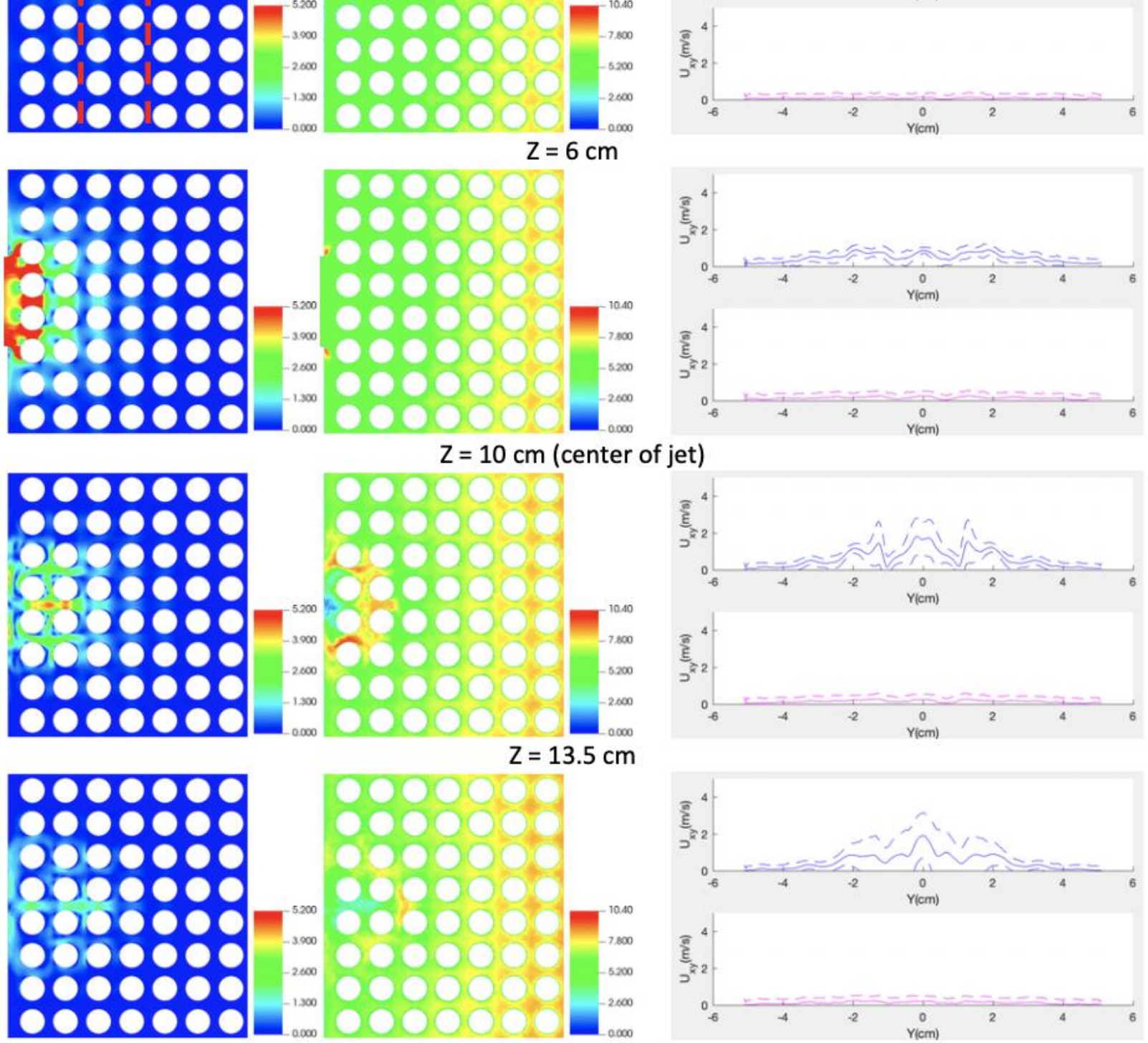

$Z=13.5 \mathrm{~cm}$
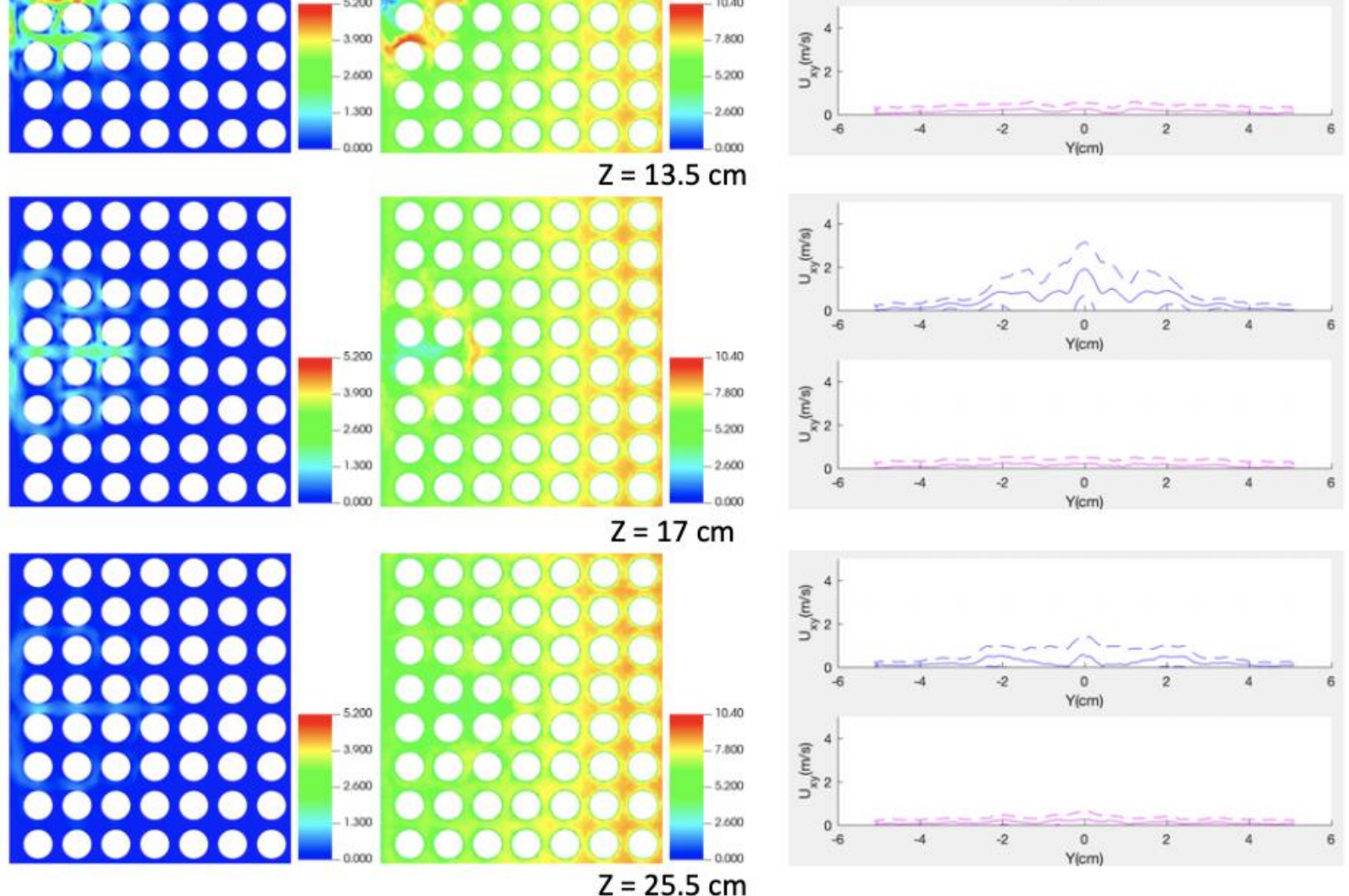

Figure 6. GC_45. Left: Transverse and streamwise velocity fields $(\mathrm{m} / \mathrm{s})$ on horizontal slices. Right: Line-plots of transverse velocity with std dev. Location shown on top left image. 

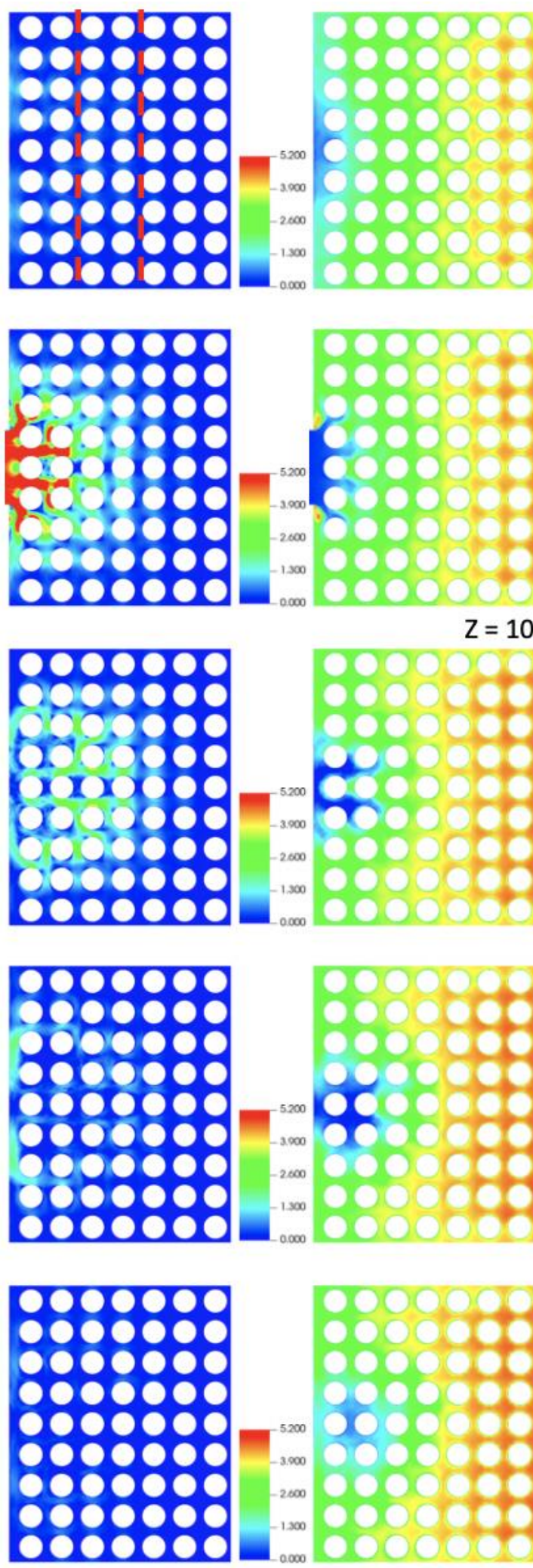

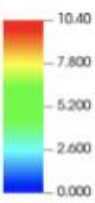

$Z=6$

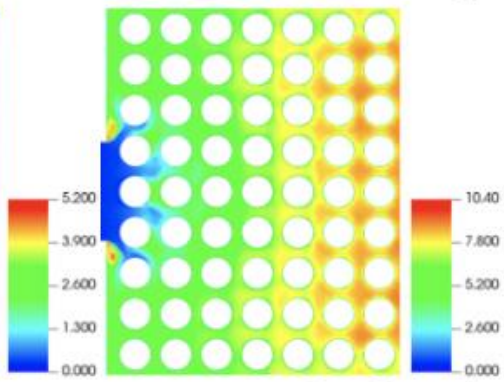

\section{$Z=10 \mathrm{~cm}$ (center of jet)}
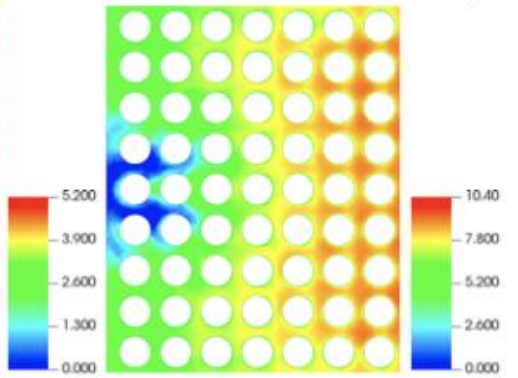

$Z=13.5$
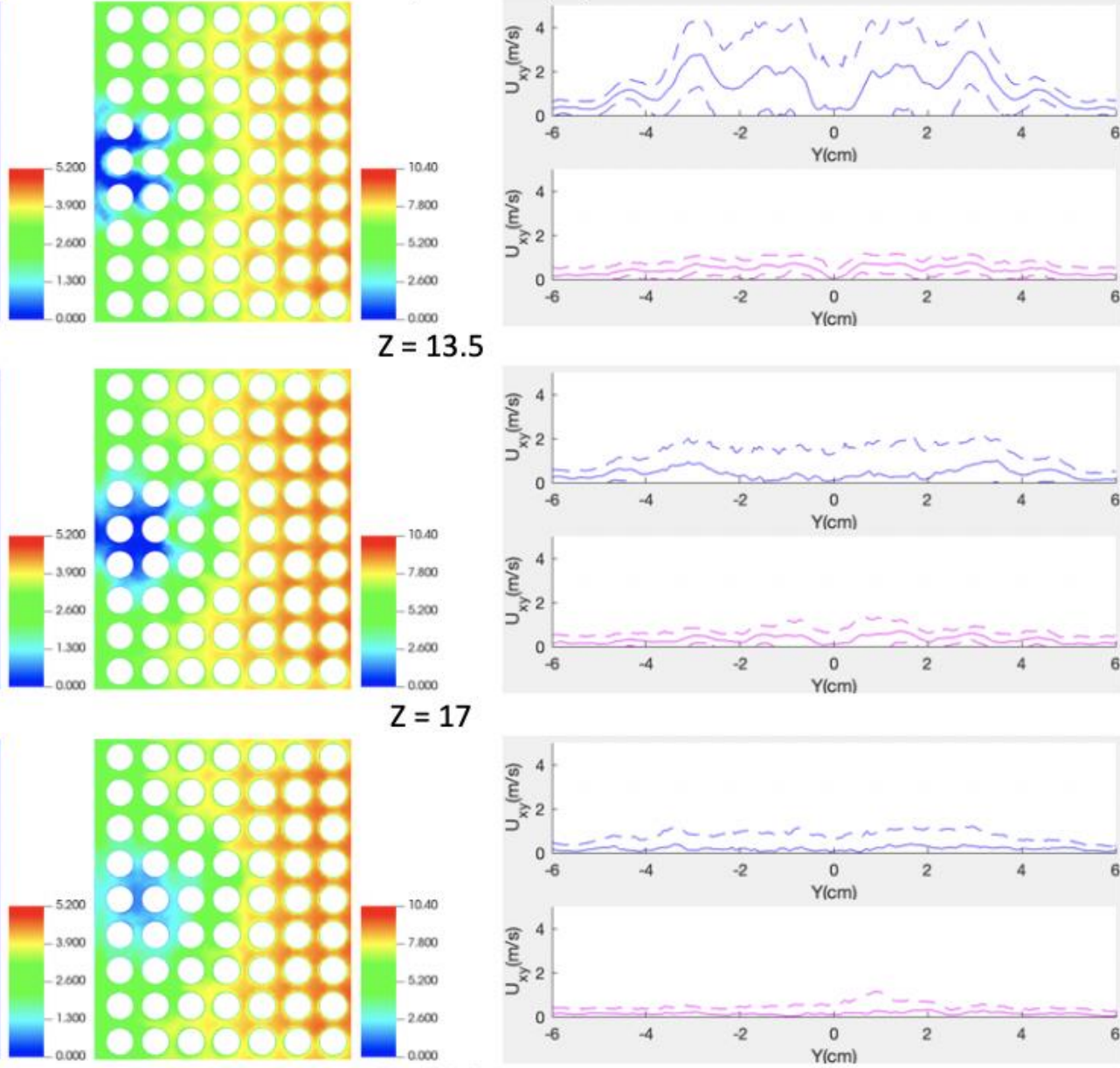

$$
Z=17
$$
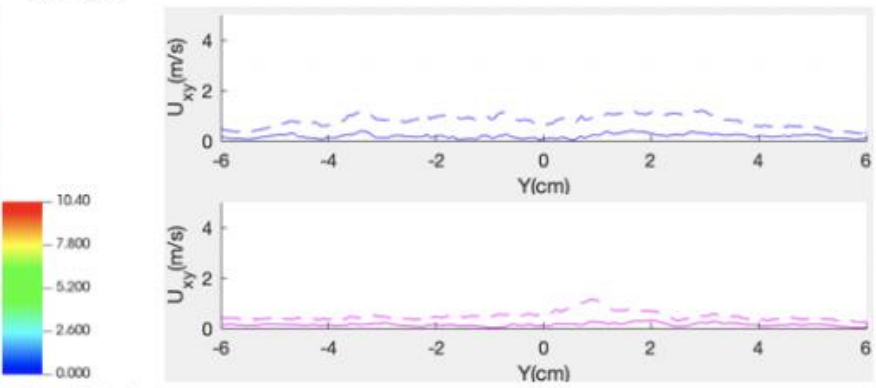

$Z=25.5$

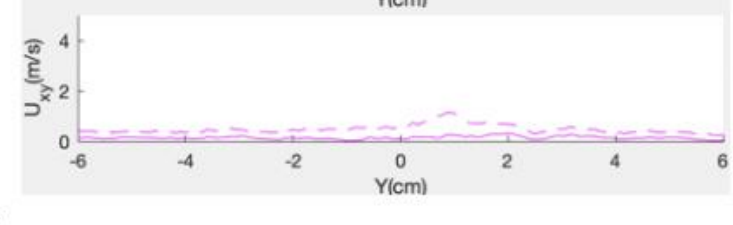

Figure 7. RC_0. Left: Transverse and streamwise velocity fields $(\mathrm{m} / \mathrm{s})$ on horizontal slices. Right: Line-plots of transverse velocity with std dev. Location shown on top left image. 

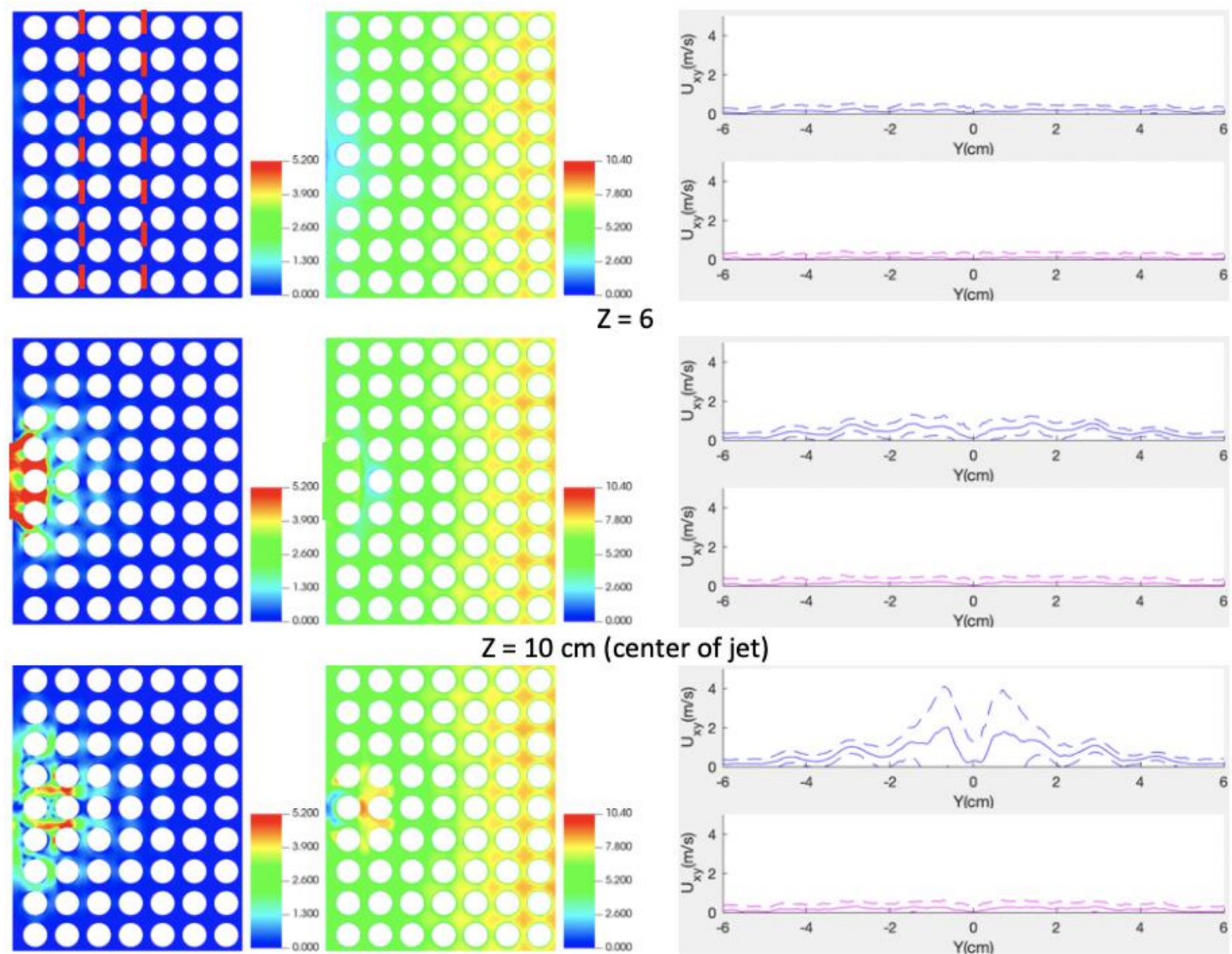

\section{$Z=10 \mathrm{~cm}$ (center of jet)}
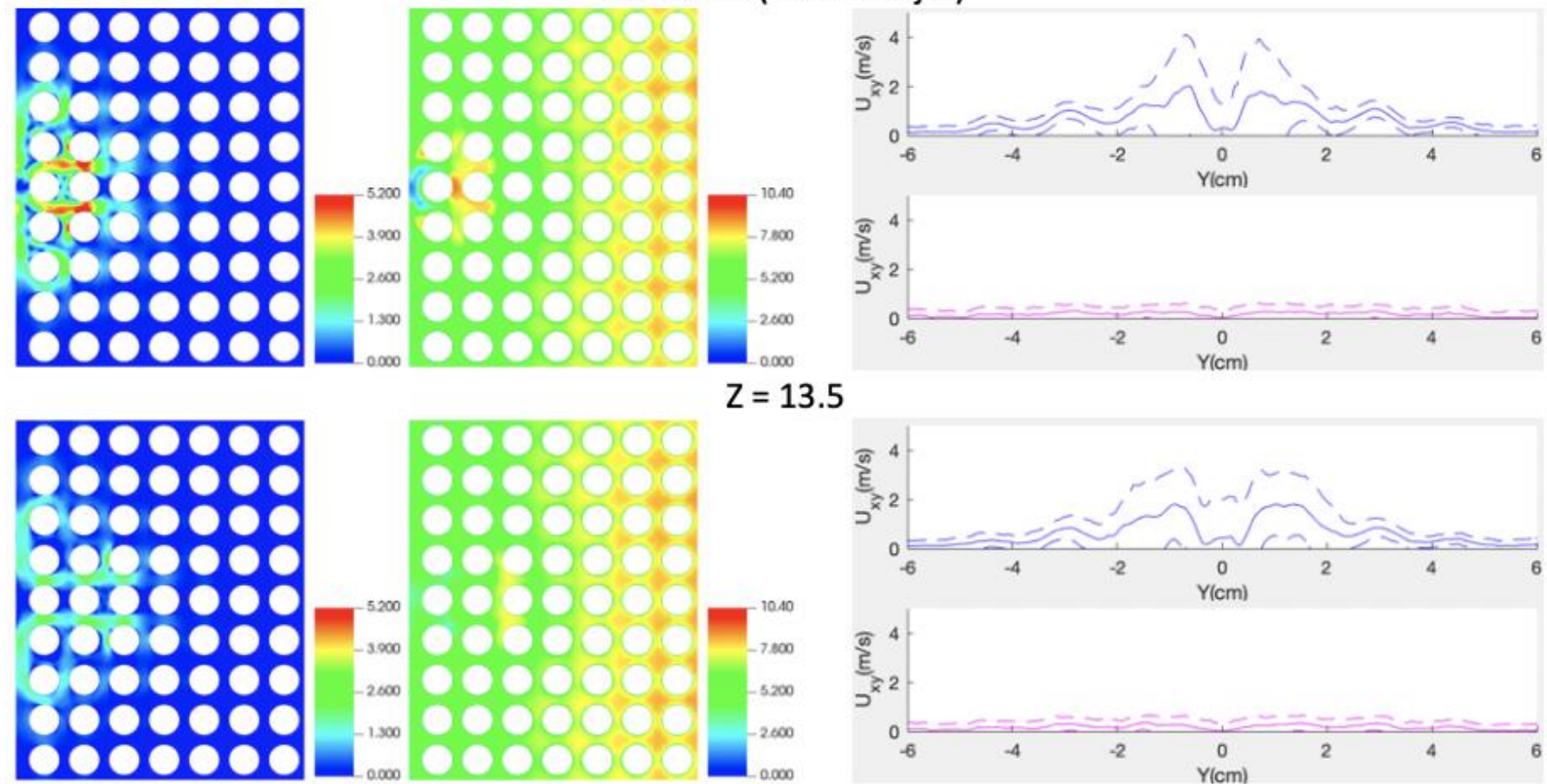

$Z=13.5$
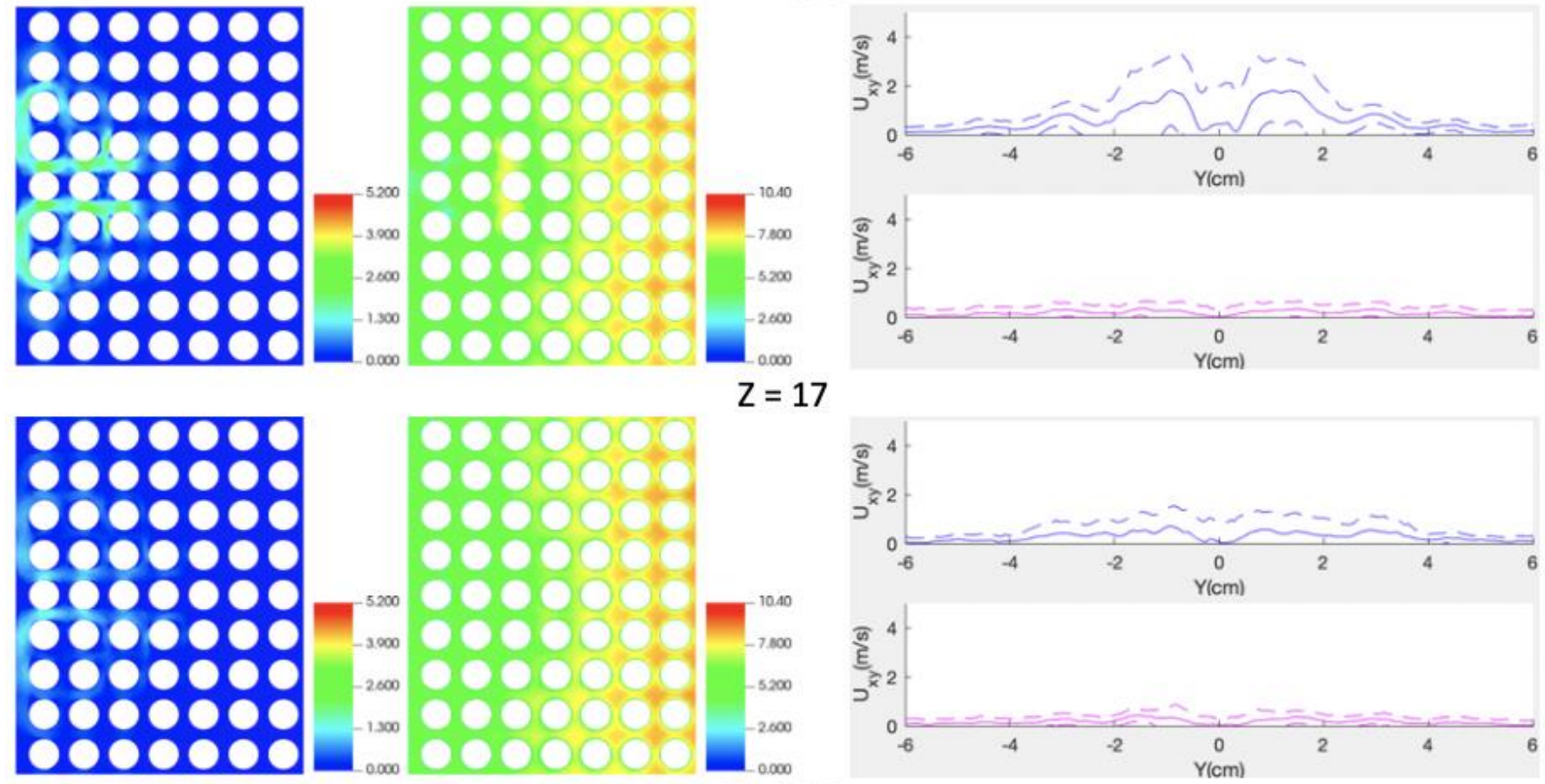

$$
Z=17
$$
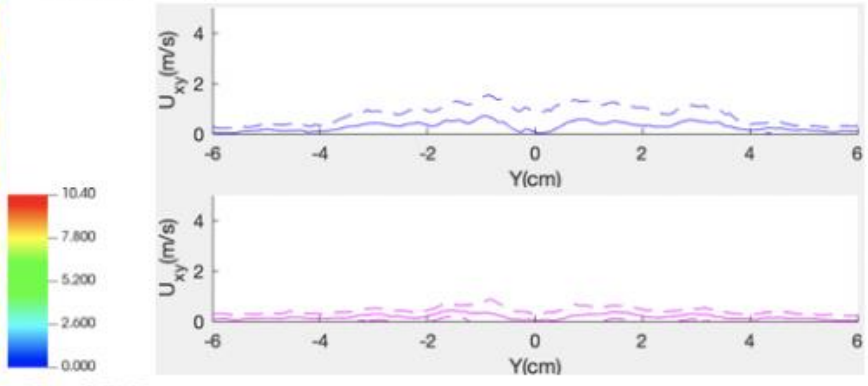

Figure 8. RC_45. Left: Transverse and streamwise velocity fields $(\mathrm{m} / \mathrm{s})$ on horizontal slices. Right: Line-plots of transverse velocity with std dev. Location shown on top left image. 
The pressure on the rod walls is calculated and averaged over every wall element face. The resolution of the gathered pressure data is therefore tied to the mesh resolution. The rod circumference contains 12 element faces. Spanwise, the mesh is 42 elements tall. The mesh is conveniently arranged in layers and the net pressure exerted on each layer is the quantity reported. The fuel rods most likely to experience crossflow vibrations are those closest to the jet inlet. Three rods from each case are selected to analyze the mean and rms pressure as a function of height. The power spectrum of the element layer with the peak net pressure is also found. Much longer simulation time is needed to resolve these power spectra to a more useful degree. Each case has experienced $\sim 0.1$ seconds of simulated time. The three rods chosen are: 1 , the rod closest to the jet, (i.e. column 1, centermost row); 2 , the rod adjacent to 1 in column 1 , further from the jet, and 3 , the rod adjacent to 1 in column 2. Figure 9 depicts the selected rods for both the GC and RC cases. Figures 10-13 show the net pressure and rms pressure exerted on the selected rods as a function of height. Also shown is the power spectrum of the pressure fluctuations at the peak pressure rms point in each case.
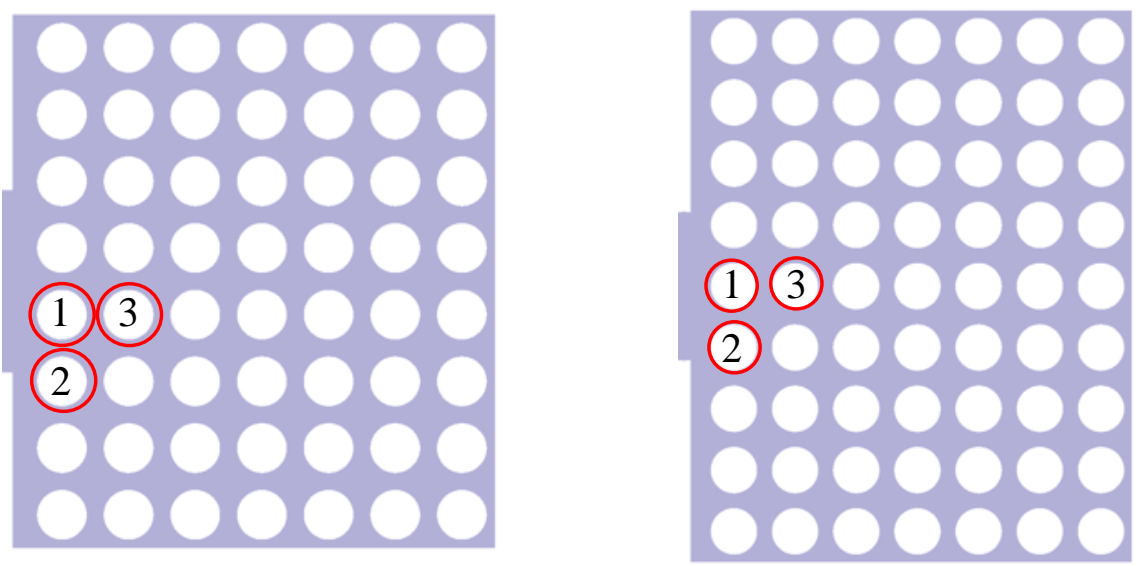

Figure 9. Rods selected for pressure analysis. Left: Gap centered case. Right: Rod centered case. 

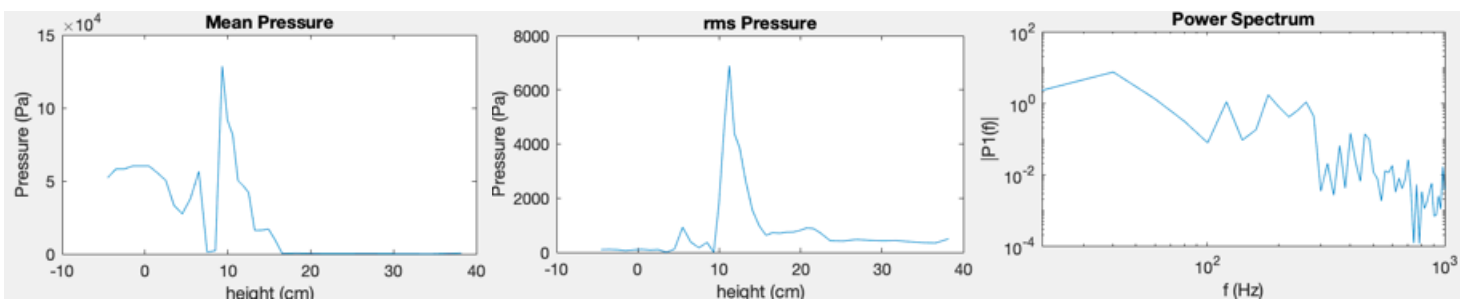

\section{GC_0 Rod 1}
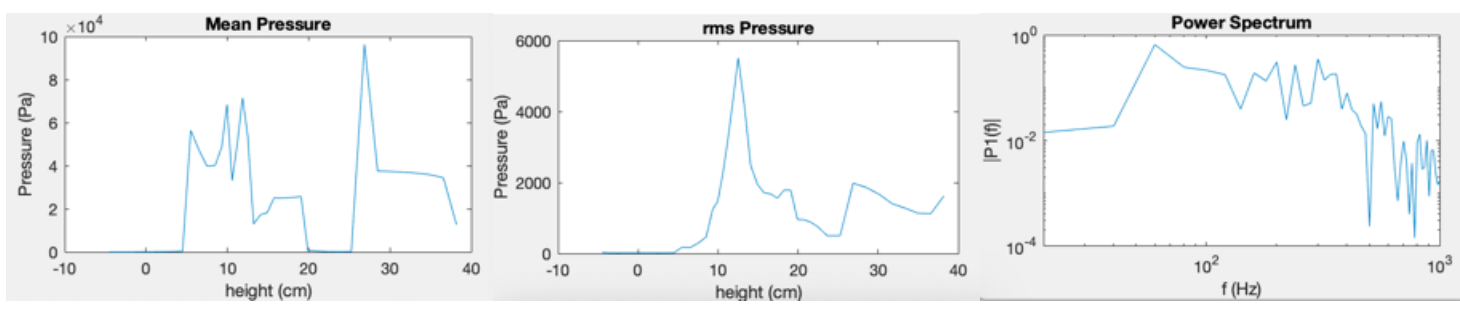

GC_0 Rod 2
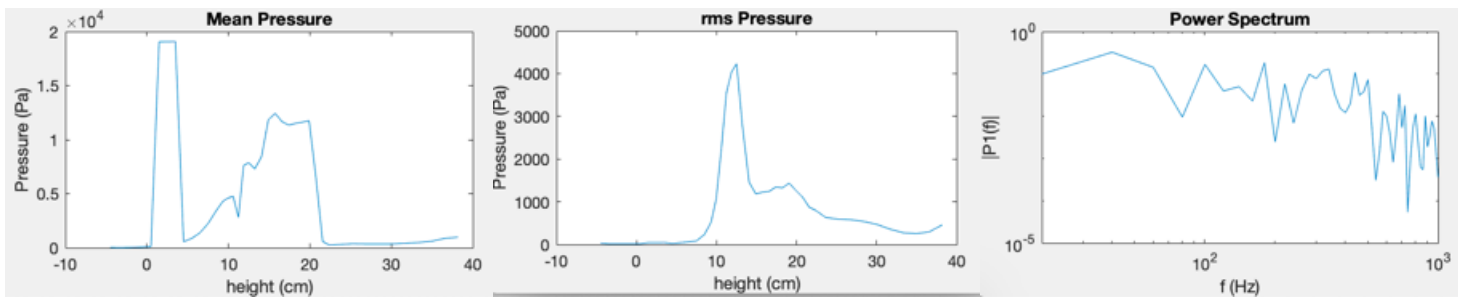

\section{GC_0 Rod 3}

Figure 10: Net pressure and rms pressure as a function of height for selected rods in GC_0. The Power spectrum from the rms pressure peak is also shown. 

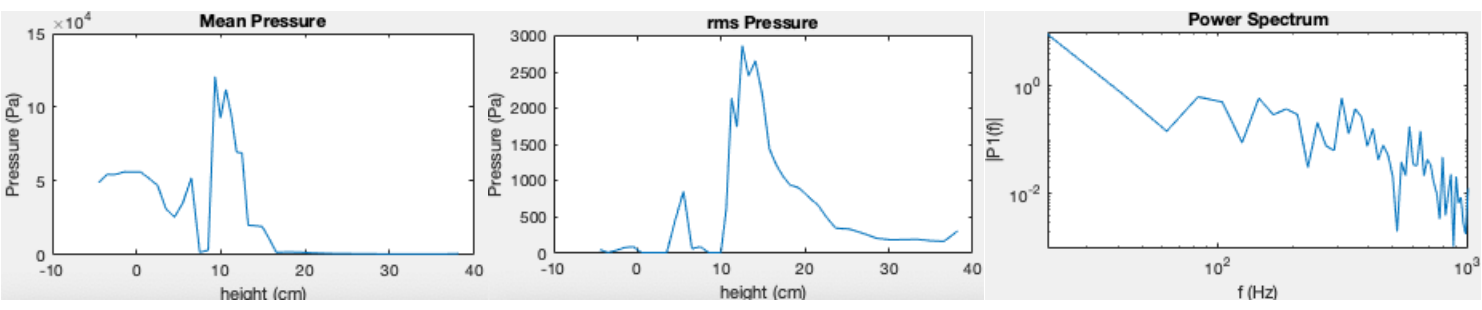

GC_45 Rod 1
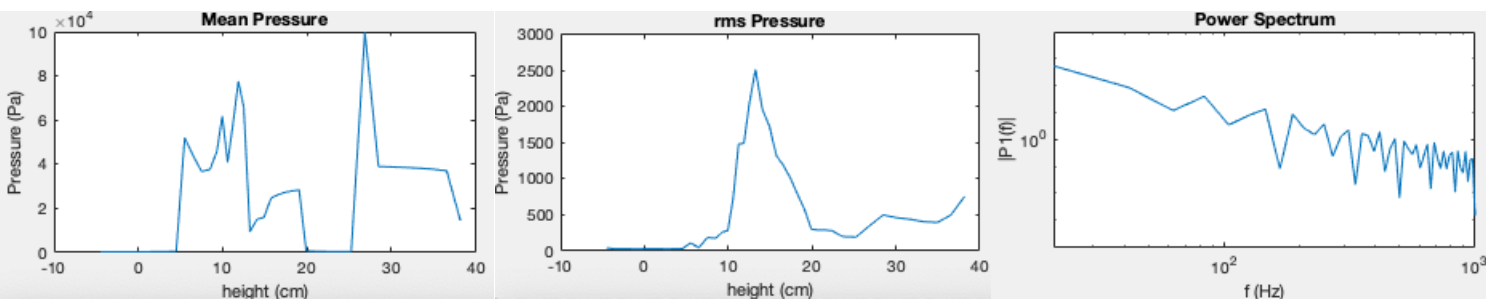

GC_45 Rod 2
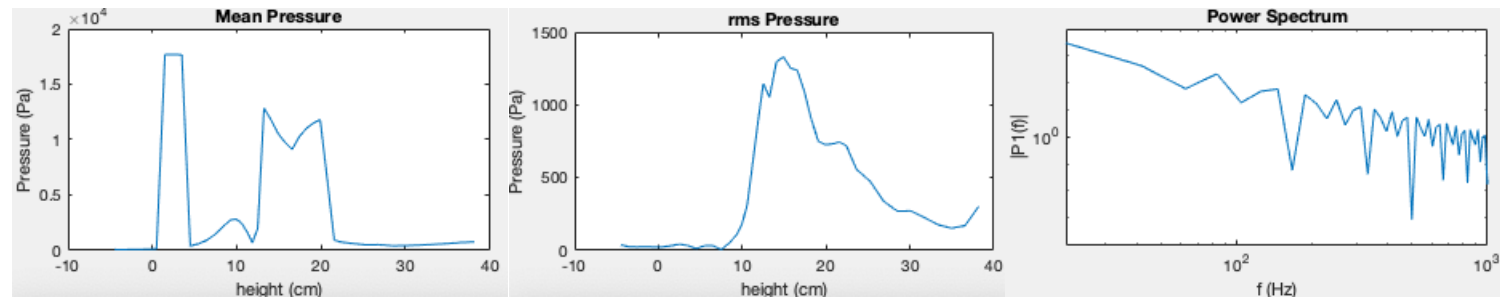

GC_45 Rod 3

Figure 11. Net pressure and rms pressure as a function of height for selected rods in GC_45. The Power spectrum from the rms pressure peak is also shown. 

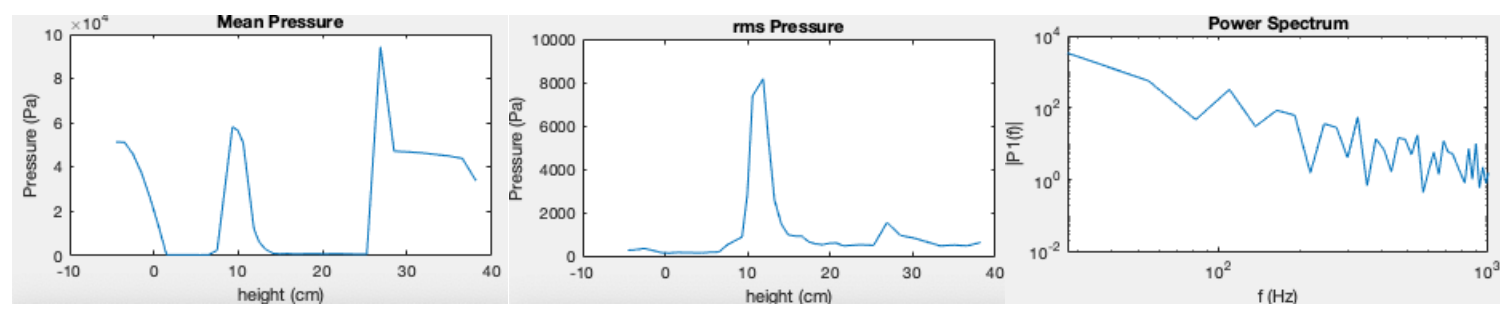

RC_0 Rod 1
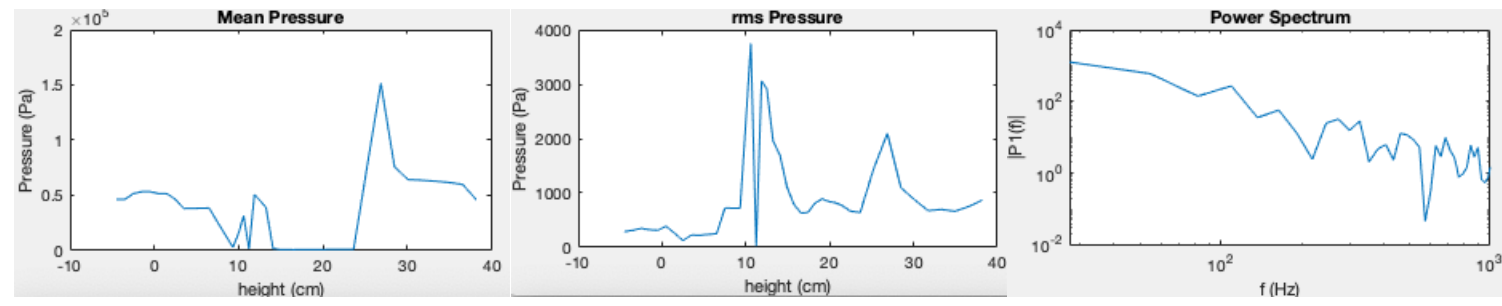

RC_0 Rod 2
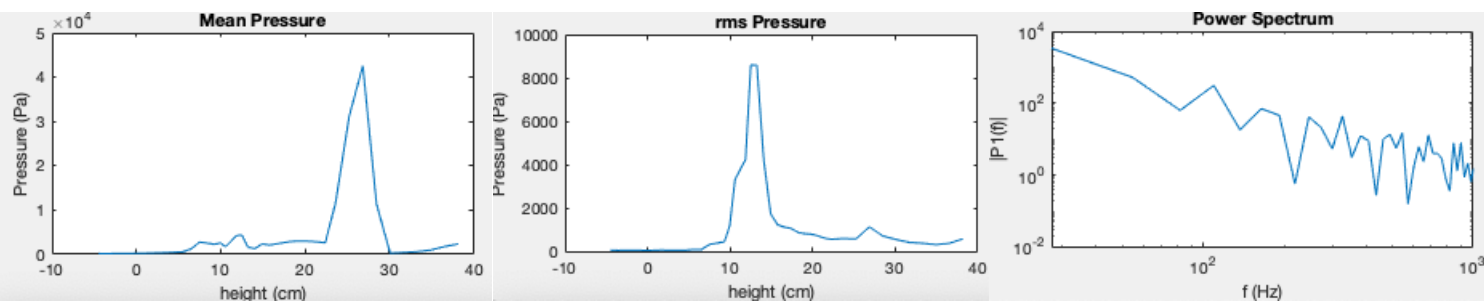

\section{RC_0 Rod 3}

Figure 12. Net pressure and rms pressure as a function of height for selected rods in RC_0. The Power spectrum from the rms pressure peak is also shown. 

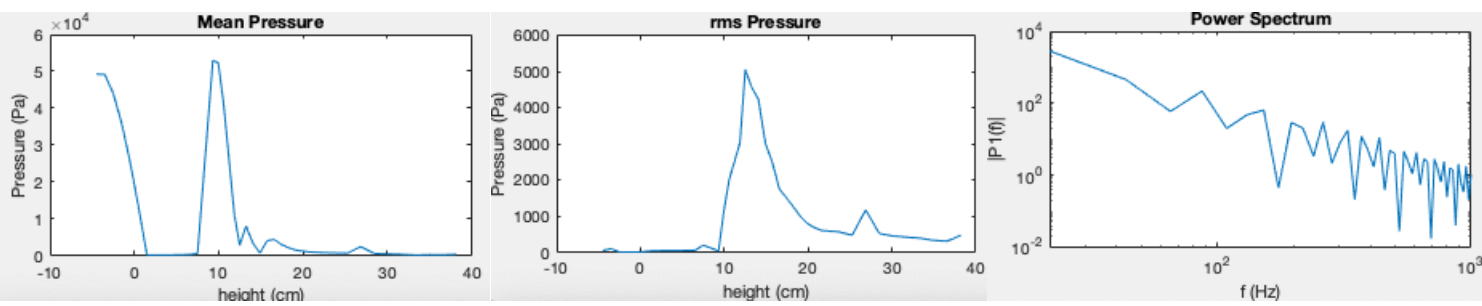

RC_45 Rod 1
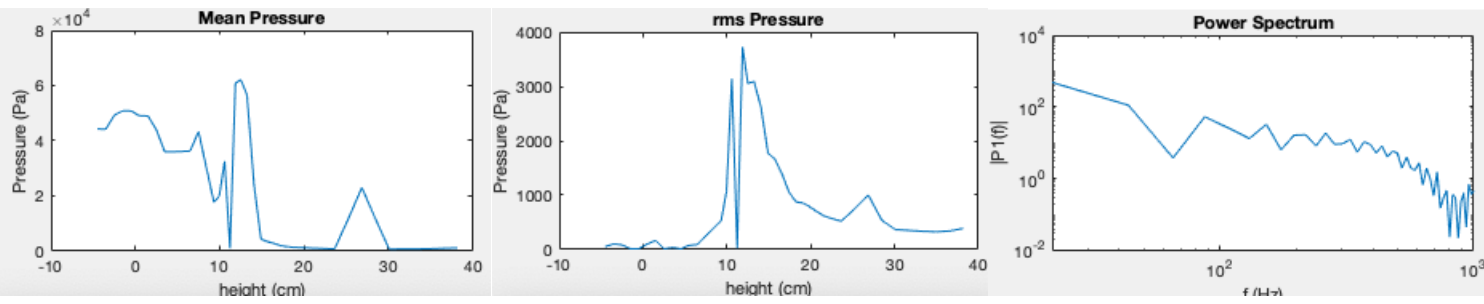

RC_45 Rod 2
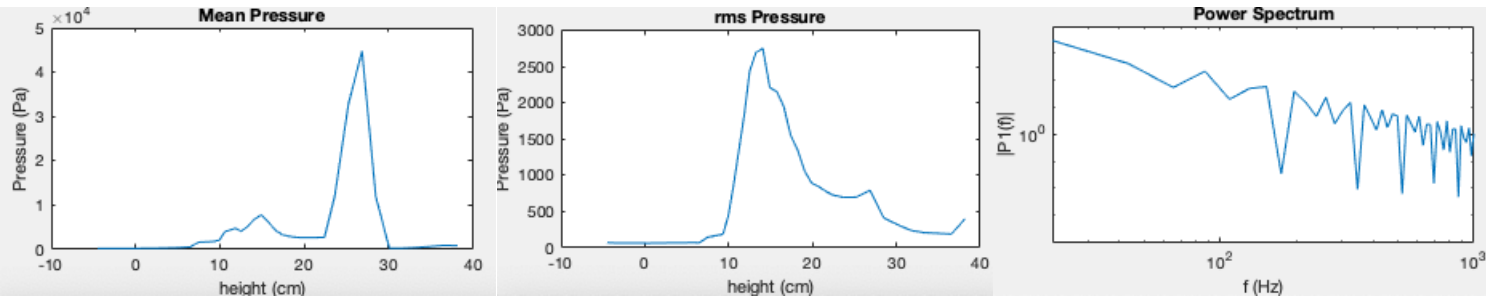

RC_45 Rod 3

Figure 13. Net pressure and rms pressure as a function of height for selected rods in RC_45. The Power spectrum from the rms pressure peak is also shown.

\subsection{Discussion}

The transverse velocity fields at various axial locations show a broad pattern of behavior in response to the impinging jet. Below the jet hole, the velocity profile is relatively undisturbed. At the jet inlet, transverse flow is induced with magnitude on the order of the axial flow. This disturbance quickly diminishes, with only minute perturbations more than 3 pitches from the jet. At increased $Z$ the disturbance moves away from the wall, decreases in peak magnitude, but increases in area. As $\mathrm{Z}$ increases the cause of transverse flow switches from flow entrainment by the jet, to a circulation around the outside of the disturbance to fill the low-pressure area in the wake of the jet.

The angle of attack of the jet, perpendicular to the flow or 45-degree angle, appears to be the more important factor affecting the behavior of the fluid. Primarily this difference comes from the perpendicular jet creating a stagnation region behind the jet. This low-pressure region induces flow reversal extending more than $10 \mathrm{~cm}$ past the jet. At $\mathrm{Z}=25.5 \mathrm{~cm}$, stagnation is still visible, while for the 45-degree case the flow has nearly settled at the same location. The recirculation region introduces several mechanisms for potential flow induced vibrations. The transverse velocity is highest near the inlet of the jet and poses a risk for crossflow induced vibrations. Further from the 
jet, both axially and laterally, the magnitude is less, but the fluctuations surpass the mean value, which can potentially activate natural frequencies. Further from the jet, even as the mean transverse velocity settles, velocity fluctuations over $1 \mathrm{~m} / \mathrm{s}$ remain. These velocity fluctuations, resulting from the recirculation, also have the potential to activate vibrations in the rods. In general while the transverse velocity near the jet is more severe for the perpendicular jet case, the potentially more troublesome behavior is the stagnation region behind the jet and the large fluctuations in transverse velocity that result.

The location of the jet hole had less effect on the general behavior of the flow, but mainly impacted the extent of the observed behaviors. The area of high transverse flow is in general smaller for the rod centered cases than for the gap centered cases. To a lesser extent the magnitude of transverse flow is observably less for the rod centered jets. The center rod forces the jet into two smaller jets as opposed to one large jet for the gap centered case. The rod centered cases notably show a greater upstream disturbance than the gap centered cases.

The rods adjacent to the wall experience the greatest transverse velocities, but the rods 2 and 3 pitches from the wall are in the wake and may experience the largest fluctuations in velocity. Rods further than 4 pitches from the wall and those to the side of the jet are of significantly less concern, barring flow phenomena not observed here.

The pressure analysis on the three rods for each case largely supports the observations from the transverse velocity analysis. In almost every case if there is a strong peak in the net pressure on the rod, it occurs at the jet inlet. As predicted in the transverse velocity analysis, however, the pressure fluctuation is greatest from the inlet to about $10 \mathrm{~cm}$ past the inlet, usually peaking around $5 \mathrm{~cm}$ past the jet inlet. These fluctuations are a greater concern for vibrations than the mean pressure. Many of the observed rods showed another peak in both mean pressure and rms pressure at around 27 to $30 \mathrm{~cm}$. This phenomenon was not predicted by the transverse velocity field analysis. At this height, the low pressure field behind the jet is dissipating. The mean transverse velocity field is dominated by flow circulating to fill the low pressure region. It is feasible that the length of the stagnation region oscillates as the flow repeatedly separates and reattaches. This oscillation may be responsible for the fluctuating pressure on the rod.

Regarding the magnitude of the rms pressures calculated, the cases with perpendicular jet flow experience the greatest pressure oscillations. The cases with a 45 degree jet angle behave largely the same characteristically, but with roughly half the magnitude of rms pressure. The rod centered cases experience greater mean and rms pressure on rod 1 than the gap centered cases. In each case rod 1 experiences by far the greatest pressure fluctuations, with the exception of RC_0, in which rod 3 has a slightly greater peak. Intuitively the rod in the most direct path of the jet is the most vulnerable to vibrations. 


\section{TerraPower Project: SAM MSFR Demo}

Under the support of DOE-NE's Nuclear Energy Advanced Modeling and Simulation (NEAMS) - Center of Excellence for Thermal Fluids Applications in Nuclear Energy, an effort had been pursued to support Molten Salt Fast Reactor (MSFR) modeling and simulation needs, as part of industry engagement efforts.

The MSFR stands out as a promising candidate among advanced nuclear reactor concepts with its improved passive safety characteristics and high thermal efficiency. In MSFRs, fissile material (fuel) is dissolved in a molten salt, which is typically chloride or fluoride based. This represents a significantly different paradigm compared to traditional light-water or other advanced reactors which use solid fuel rods. As the fuel in an MSFR is already in a liquid state, the melting point of the fuel is no longer a limiting factor in the reactor design, completely eliminating a major safety concern. However, this brings its own set of challenges. For example, one major challenge that comes with the MSFR design is the configuration of multiple inlet channels entering the bottom of the core at relatively high velocities and ensuring the active core region sees stable upward flow without large-scale recirculation that could induce temporal and spatial instabilities in reactor power distribution. Advanced modeling capabilities are demanded to be able to simulate and optimize the MSFR system.

As the key system analysis code developed under the NEAMS program, the System Analysis Module (SAM) [10] is selected in this study to develop a reference primary loop model for the MSFR using its latest improvements on multi-dimensional flow modeling and 1D-3D coupling techniques. More specifically, the MSFR core is to be modeled by a two-dimensional model to resolve the large-scale fluid movement inside the core while the external circuits are represented by one-dimensional models for efficient calculation. A reference standard problem of the reactor primary loop model is foundational to the methodologies employed by the industry user community to verify the adequacy of computer codes and evaluation models. This Chapter details the corresponding SAM model setups, the progress and preliminary results obtained so far, as well as the technical challenges identified.

\subsection{SAM Model Setups}

SAM is under development at Argonne National Laboratory to provide fast-running, improved-fidelity, whole-plant transient analyses for advanced non-LWRs. The initial development focus was on SFRs, but more recently, SAM has been expanded to support liquid-salt-cooled and liquid-salt-fueled reactor technologies. SAM leverages modern advanced software environments and numerical methods and is well suited to be further developed as a key tool for MSFR modeling \& simulation at the reactor plant scale and for reactor safety analysis.

The geometric design of MSFR core is based on a model previously studied under the European EVOL program [11]. Figure 14 shows the detailed dimensions of the $2 \mathrm{D}$ core. Since the core is symmetrical, only half of the domain is illustrated. The core height is $1.8 \mathrm{~m}$ at the centerline and $2.0 \mathrm{~m}$ in the peripheral region. The core radius ranges from $0.94 \mathrm{~m}$ to $1.25 \mathrm{~m}$. The radius of inlet and outlet channels is set to be $0.25 \mathrm{~m}$. A vertical distance of $1.25 \mathrm{~m}$ is kept between the domain outlet and inlet, where the heat exchanger would be placed to cool down the fuel salt. The inlet and outlet surfaces are aligned horizontally and constant pressure boundary condition is assumed at the core outlets, which help avoid complex and potential backward flow at the boundary. Noslip condition is applied to all walls. The resulting mesh is exhibited in Figure 15 with 2,180 cells. 
The geometric model and mesh are both produced by the open source meshing software, SALOME [13].

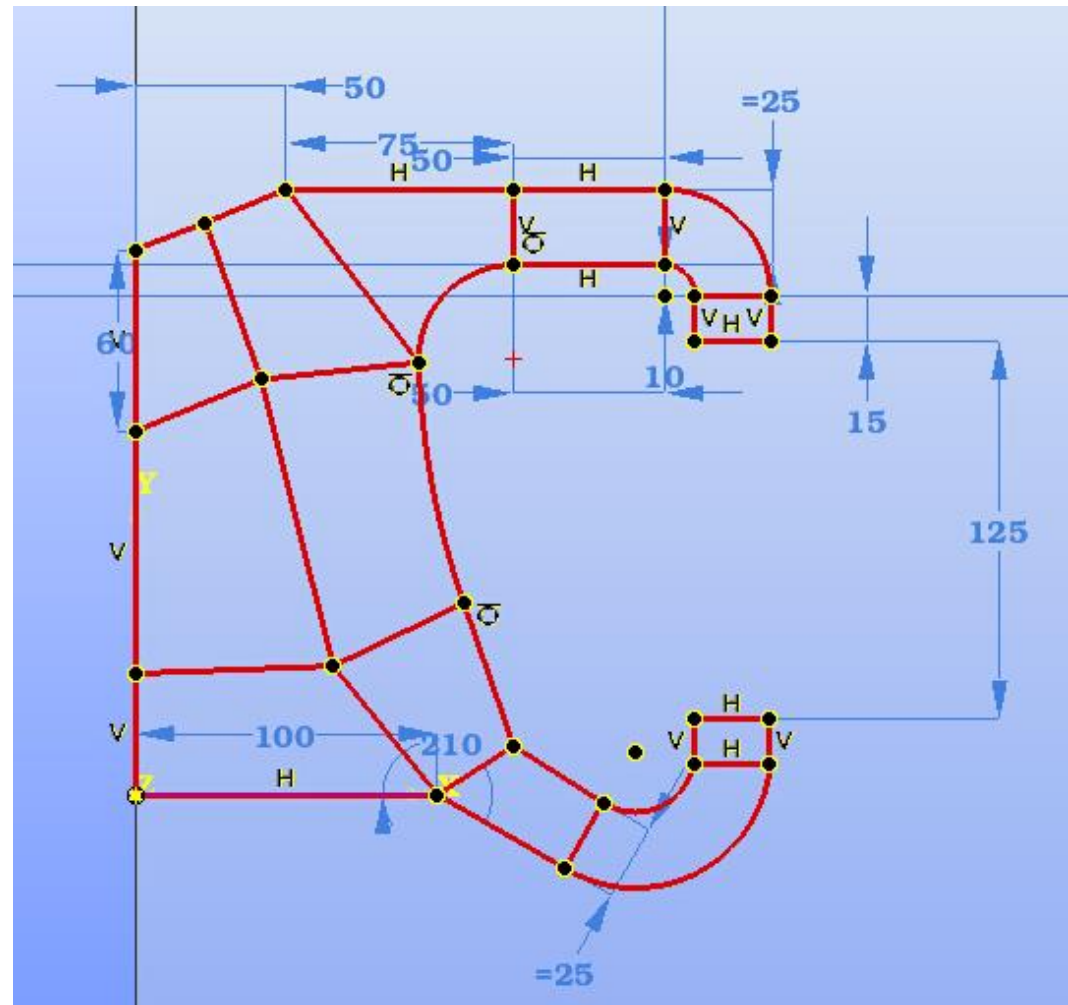

Figure 14. The dimensions of MSFR core (the length unit: $\mathrm{cm}$ ).

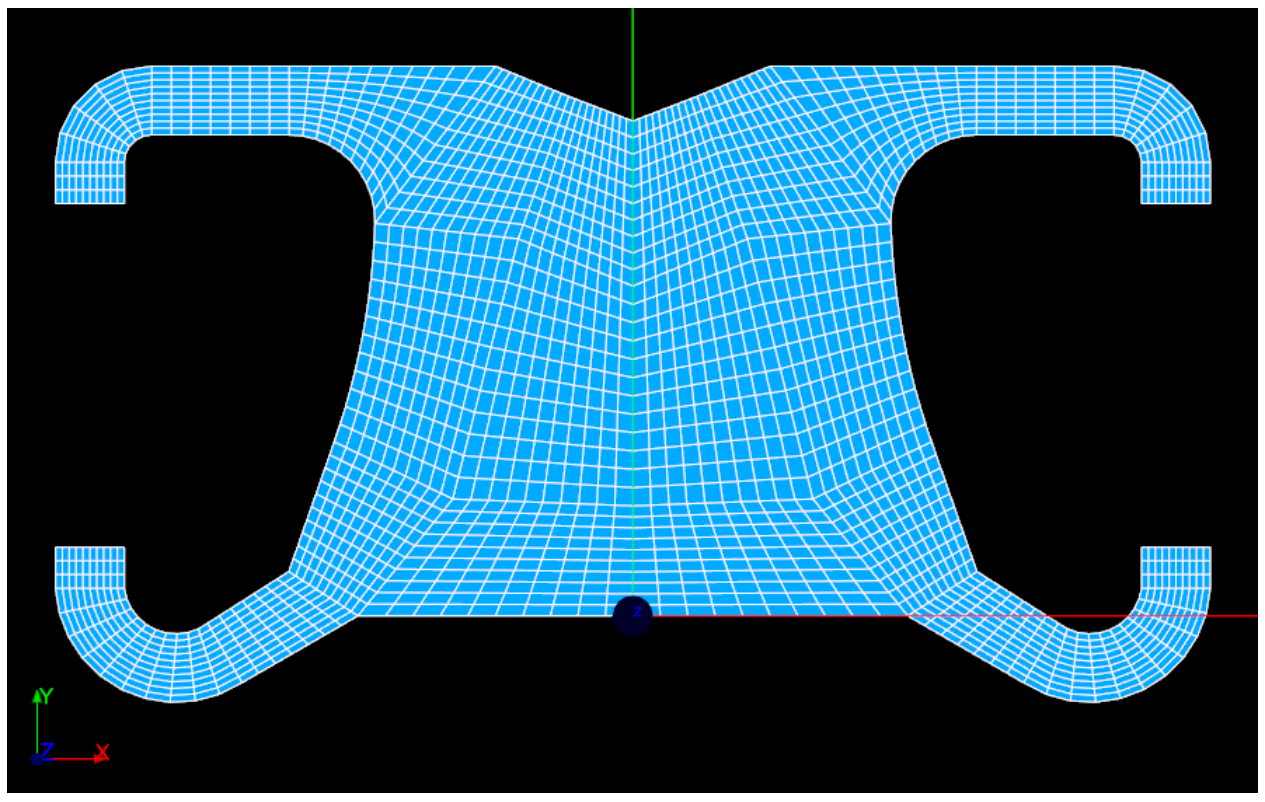

Figure 15. The computational grid of the 2D MSFR core. 
The primary salt containing the fuel is chosen to be $\mathrm{LiF}_{-} \mathrm{ThF}_{4}$ with molar fractions of $0.775-0.225$ following the studies done under the EVOL project. The corresponding thermophysical properties are listed in Table 3. However, the coolant salt flowing through the heat exchanger secondary side

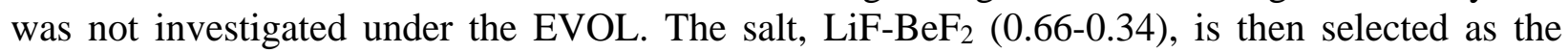
coolant salt, which was previously used in the ORNL MSRE. [13] The related thermophysical properties can be found in Table 4. The thermophysical properties of the fuel salt are implemented in SAM as the user-specified equations of state (EOS), which can be utilized by various SAM components, such as the HXs, pumps, and connecting pipes. FLiBe salt properties are available as built-in fluid property models in SAM.

Table 3. Thermophysical properties of the primary salt.

\begin{tabular}{rccc} 
& & Unit & LiF-ThF 4 \\
& & & $\mathbf{0 . 7 8 - 0 . 2 2}$ \\
& & $\mathrm{K}$ & 838 \\
\hline Melting temperature & $T_{\text {melting }}$ & $\mathrm{K}$ & 1874 \\
Boiling temperature & $T_{\text {boiling }}$ & $\mathrm{Kg} / \mathrm{m}^{3}$ & $4983.56-0.882 \cdot \mathrm{T}$ \\
Density & $\rho$ & $\mathrm{mPa} \cdot \mathrm{s}$ & $\rho\left(5.54 \times 10^{-5} \mathrm{exp}(3689 / \mathrm{T})\right)$ \\
Dynamic viscosity & $\mu$ & $\mathrm{W} /(\mathrm{m} \cdot \mathrm{K})$ & $0.928+8.397 \times 10^{-5} \cdot \mathrm{T}$ \\
Thermal conductivity & $k$ & $\mathrm{~J} /(\mathrm{kg} \cdot \mathrm{K})$ & $-1111+2.78 \cdot T$ \\
\hline Specific heat capacity & $c_{p}$ & & \\
\hline
\end{tabular}

Table 4. Thermophysical properties of the intermediate salt.

\begin{tabular}{rccc}
\hline & & Unit & LiF-BeF \\
& & & $\mathbf{0 . 6 6 - 0 . 3 4}$ \\
\hline Melting temperature & $T_{\text {melting }}$ & $\mathrm{K}$ & 728 \\
Density & $\rho$ & $\mathrm{kg} / \mathrm{m}^{3}$ & $2214.0-0.44 \cdot T$ \\
Dynamic viscosity & $\mu$ & $\mathrm{mPa} \cdot \mathrm{s}$ & $0.116 \mathrm{exp}(3755 / T)$ \\
\hline Thermal conductivity & $k$ & $\mathrm{~W} /(\mathrm{m} \cdot \mathrm{K})$ & 1.1 \\
\hline Specific heat capacity & $c_{p}$ & $\mathrm{~J} /(\mathrm{kg} \cdot \mathrm{K})$ & 2390 \\
\hline
\end{tabular}


The heat exchanger modelled adopts a counterflow shell-and-tube design. The height of heat exchanger is $1.2 \mathrm{~m}$. The tube has a diameter of $1.27 \mathrm{~cm}(0.5 \mathrm{in})$ and a thickness of $1.067 \mathrm{~mm}$ following the MSRE specifications [15]. The flow areas and HX height are adjustable parameters herein to achieve desired heat removal rate. The HX material is Hastelloy ${ }^{\circledR} \mathrm{N}$ alloy with the thermophysical properties listed in Table 5.

Table 5. Thermophysical properties of Hastelloy ${ }^{\circledR} \mathrm{N}$ alloy.

\begin{tabular}{rccc}
\hline & & Unit & Hastelloy ${ }^{\circledR}$ alloy \\
\hline Melting temperature & $T_{\text {melting }}$ & $\mathrm{K}$ & 1573 \\
Density & $\rho$ & $\mathrm{kg} / \mathrm{m}^{3}$ & 8860 \\
Shermal conductivity & $k$ & $\mathrm{~W} /(\mathrm{m} \cdot \mathrm{K})$ & 23.6 \\
Specific heat & $c_{p}$ & $\mathrm{~J} /(\mathrm{kg} \cdot \mathrm{K})$ & 578 \\
\hline
\end{tabular}

The heat generation rate specified has an analytical form given by Eq. (2). Figure 16 shows the distribution of heat generation rate inside the 2D core. In addition to the constant pressure $\mathrm{BC}$ at core outlets and no-slip condition at walls, the core inlet velocity is set to $1.577 \mathrm{~m} / \mathrm{s}$ and the inlet temperature is $900 \mathrm{~K}$.

$$
q_{v}=7.838 \times 10^{8} \exp \left(-5 *\left(x^{2}+(y-1.0)^{2}\right)\right)
$$

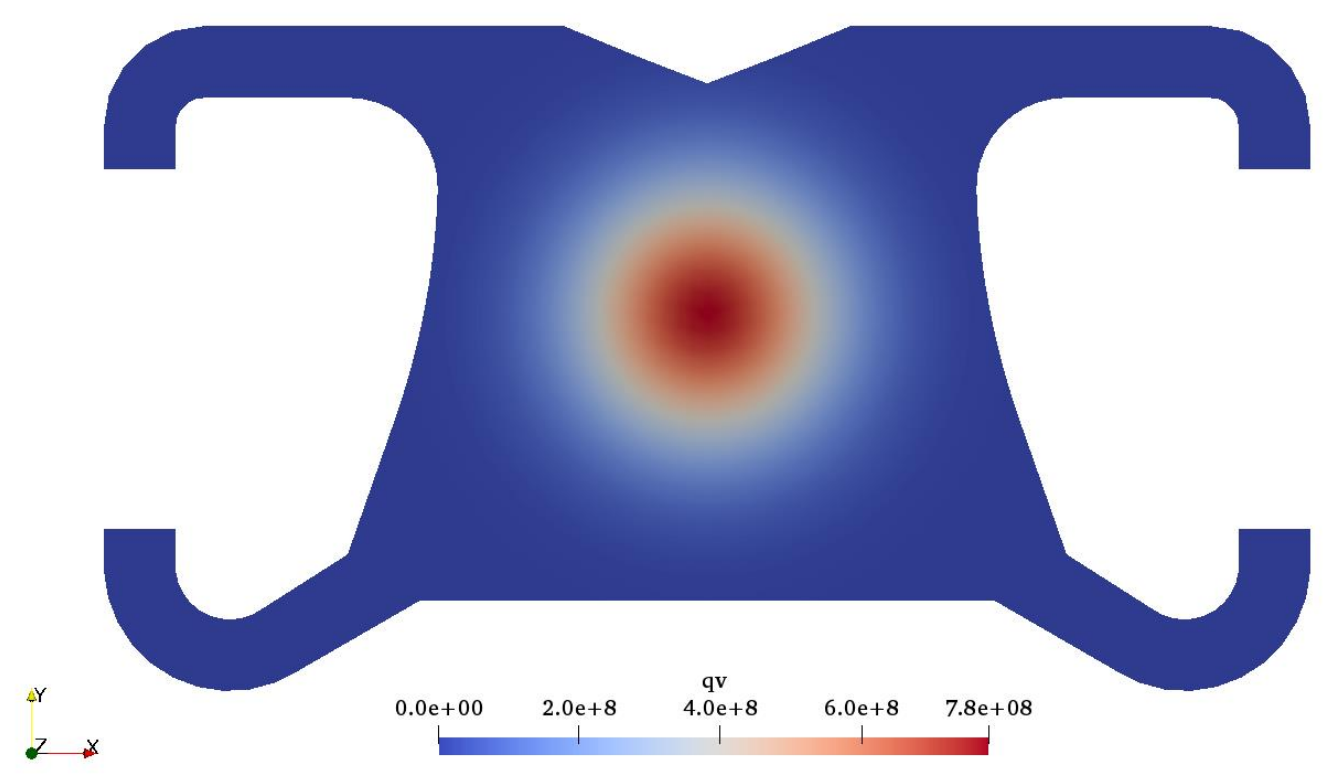

Figure 16. The distribution of heat generation rate in the MSFR core. 
As shown in Figure 17, there are 2 external circuits connected to the MSFR core. Each circuit consists of one heat exchanger, one pump, and the connecting pipes. Considering the 16 external circuits proposed in EVOL MSFR designs, the total flow rate of $18932.2 \mathrm{~kg} / \mathrm{s}$ (for the full core) leads to a flow rate of $1183.3 \mathrm{~kg} / \mathrm{s}$ in each exchanger. The resulting average velocity is approximately $1.577 \mathrm{~m} / \mathrm{s}$ for the fuel salt at the HX primary side, which matches the core inlet velocity. The external circuits are modeled with designated SAM components (0-D or 1-D), including PBHeatExchanger, PBPump, and PBOneDFluidComponent.

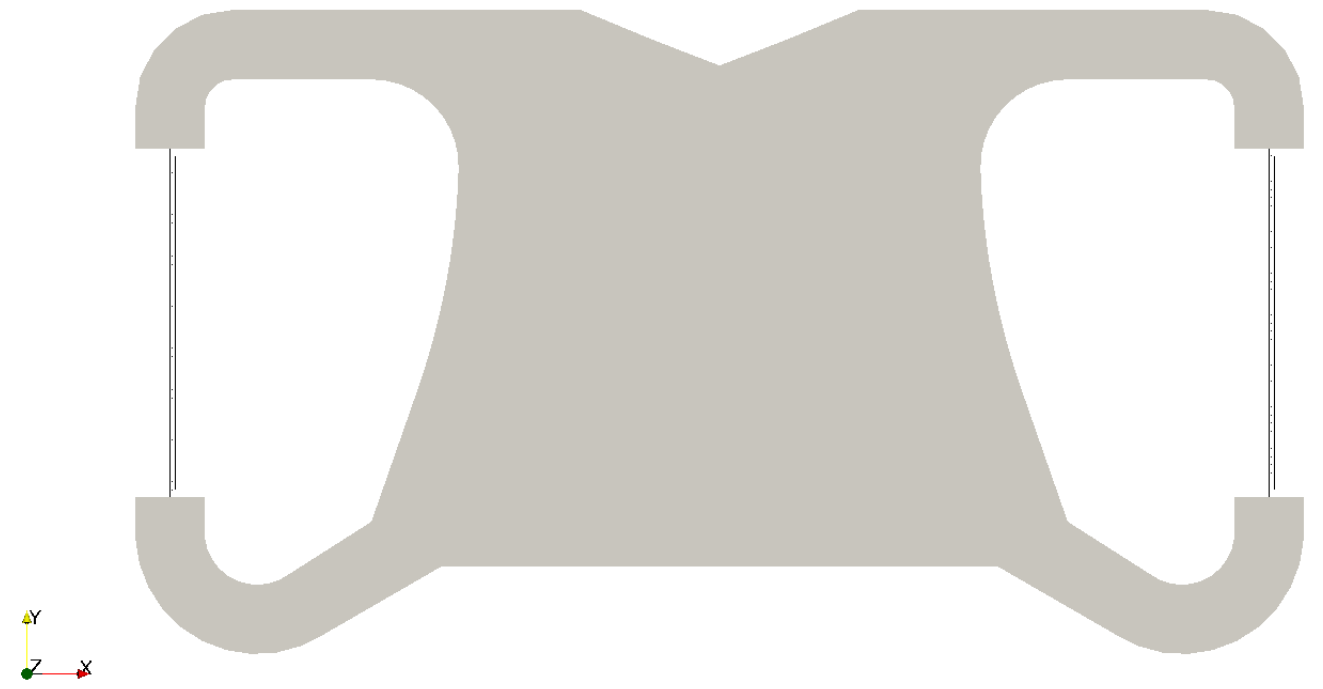

Figure 17. The complete MSFR primary loop with 2-D core and 1-D circuits (represented by black lines).

\subsection{Preliminary results.}

Prior to the integrated 1D-2D simulation cases, standalone 2-D core model and 1-D external circuits model are first established and tested. All the inlets and outlets of 2-D core are given Dirichlet boundary conditions. For instance, fixed velocity and temperature are specified at the MSFR core inlets while fixed pressure is given at the core outlets. Again, taking the EVOL MSFR designs as the reference [11], the nominal power is $3000 \mathrm{MW}$, which lead to a peak heat generation rate of $7.84 \mathrm{E}+08 \mathrm{~W} / \mathrm{m}^{3}$. A mixing length turbulence model is tuned in the standalone 2-D core model to achieve similar velocity and temperature fields available in the literature [11]. As mentioned earlier, the HX flow areas as well as the secondary coolant salt temperature and speed are kept as adjustable parameters. As listed in Table 6. these parameters are tuned such that the $\mathrm{HX}$ can successfully cool down the fuel salt in primary loop from $\sim 1007 \mathrm{~K}$ at the core outlet to $900 \mathrm{~K}$ at the core inlet. By setting the inlet temperature of $\mathrm{HX}$ secondary flow to $863 \mathrm{~K}$, the required flow speed has to be at least $2.86 \mathrm{~m} / \mathrm{s}$ to achieve the expected heat removal efficiency. The pump head is also adjusted such that the pressure change across the 1-D circuit matches the pressure difference between 2-D core inlet and outlet. The steady-state pressure distribution is illustrated in Figure 18 and significant pressure loss takes place at the inlet and outlet elbows. It is also noticed that the current SAM fluid modeling still has difficulty in accurately predicting fluid flows with high Reynolds numbers. For instance, though the overall temperature distribution obtained in the 2-D core agrees well with the CFD reference, there is still some discrepancy along the outer wall where CFD reference reports a local hot region (as shown in Figure 19). The related 
discrepancies will hopefully be mitigated or avoided once more advanced models are available in SAM to better account for the turbulence effect.

Table 6. The flow temperatures at heat exchanger inlets and outlets.

\begin{tabular}{cccc}
\hline & Unit & Primary side & Secondary side \\
\hline Inlet temperature & $\mathrm{K}$ & 1007.5 & 863.0 \\
& & & 893.8 \\
\hline Outlet temperature & $\mathrm{K}$ & 900.1 & \\
\hline
\end{tabular}

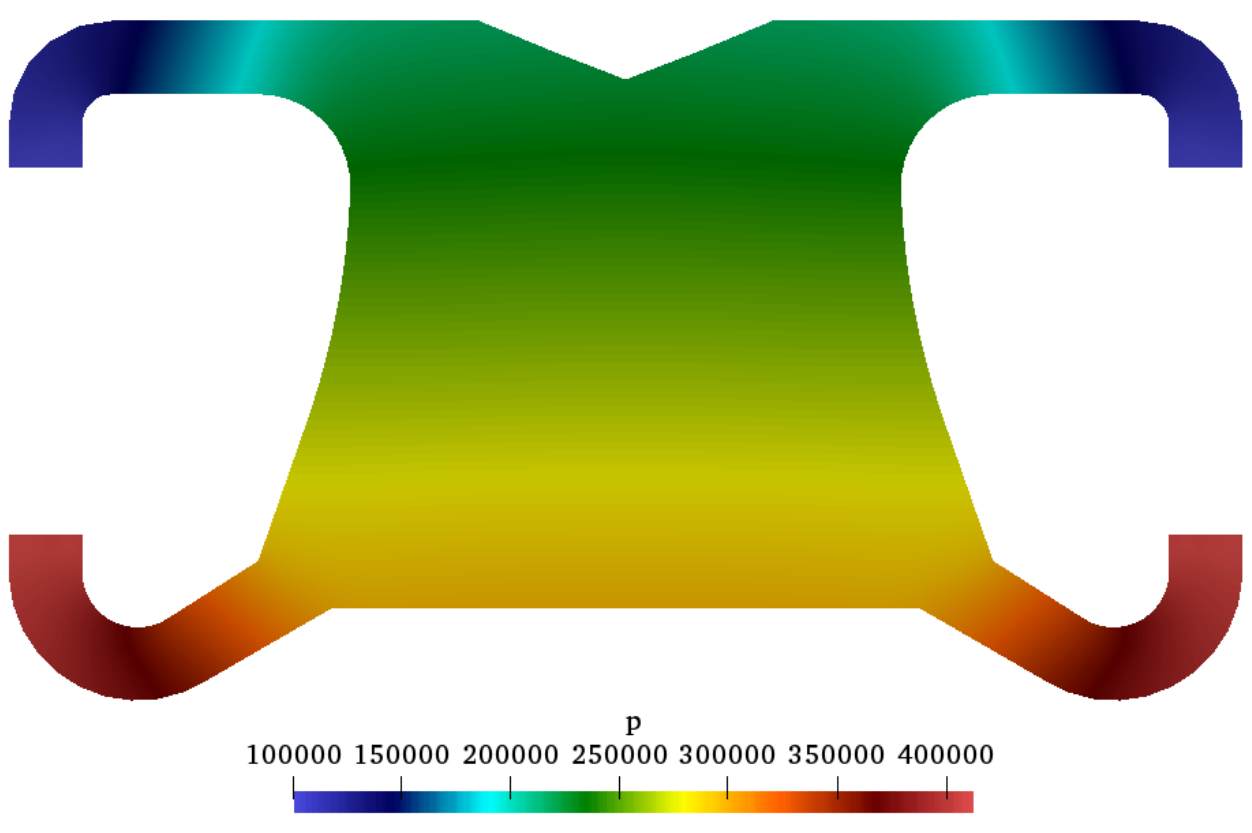

Figure 18. The steady-state pressure distribution in the $2 \mathrm{D}$ core. 


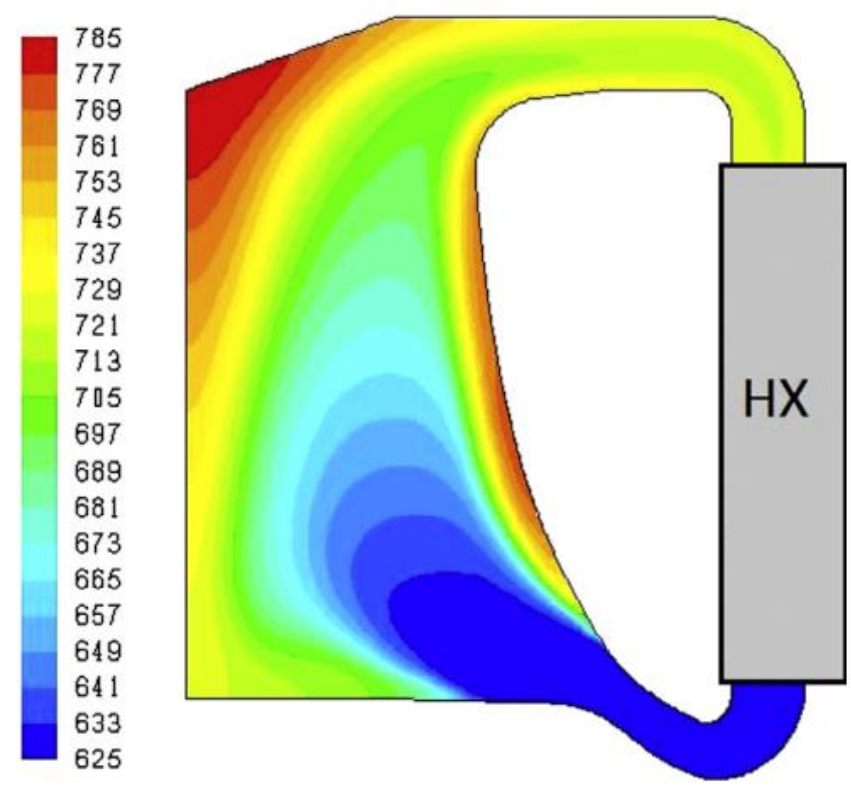

(b) Fuel salt temperature distribution $\left[{ }^{\circ} \mathbf{C}\right]$

Figure 19. The reference temperature solution from CFD calculations in the 2D MSFR core.

The MOOSE multiApps framework is then employed to create the coupled SAM model for MSFR system, which supports one master application and one or more subject applications. The two types of multiApps application are to be referred as master- and sub-app from now on. In the current study, the master model consists of the 2-D MSFR core with two inlets and two outlets as shown in Figure 15., while the one sub-app model contains the two external 1-D circuits. Master and subapp are coupled at the core inlets and outlets with matched flow condition parameters, such as the pressure, velocity, and temperature. The data exchange between master and sub-app can be manually controlled. To expedite the convergence of SAM model, a two-step approach is adopted. A semi-coupling case is first carried out with only the one-way data transfer from the master to the sub-app, and the checkpoints are saved when both the master and sub-app models reach the steady state. The fully coupled case is then restarted from the previously obtained steady-state solutions with the two-way data transfer. This way, the steady state of the fully coupled case can be quickly achieved. Figure 20 and Figure 21 exhibits the steady-state temperature and velocity distributions in the MSFR system. The peak temperature region is located in the upper side along the core centerline, and the overall temperature distribution is consistent with the CFD results reported by Rouch et al. [11]. The outlet temperature is $1007 \mathrm{~K}$. The fuel salt is cooled down through the HXs and return to the core from bottom inlets. The velocity field is shown in Figure 21 , and the arrows are scaled by the local velocity magnitude. It is noticed that the large-scale flow recirculation is avoided in the reference core configuration. 


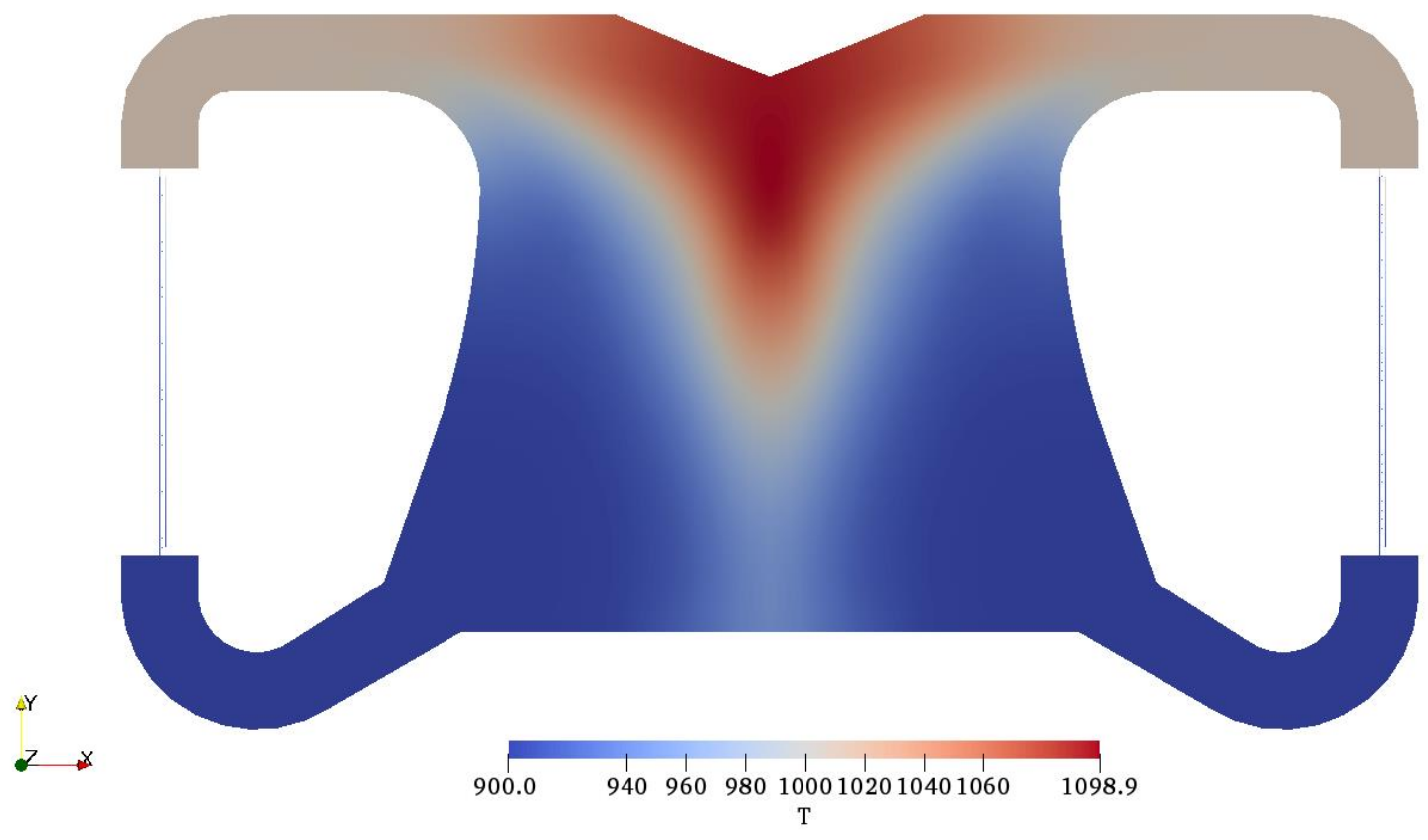

Figure 20. The steady-state temperature distribution in the MSFR system.

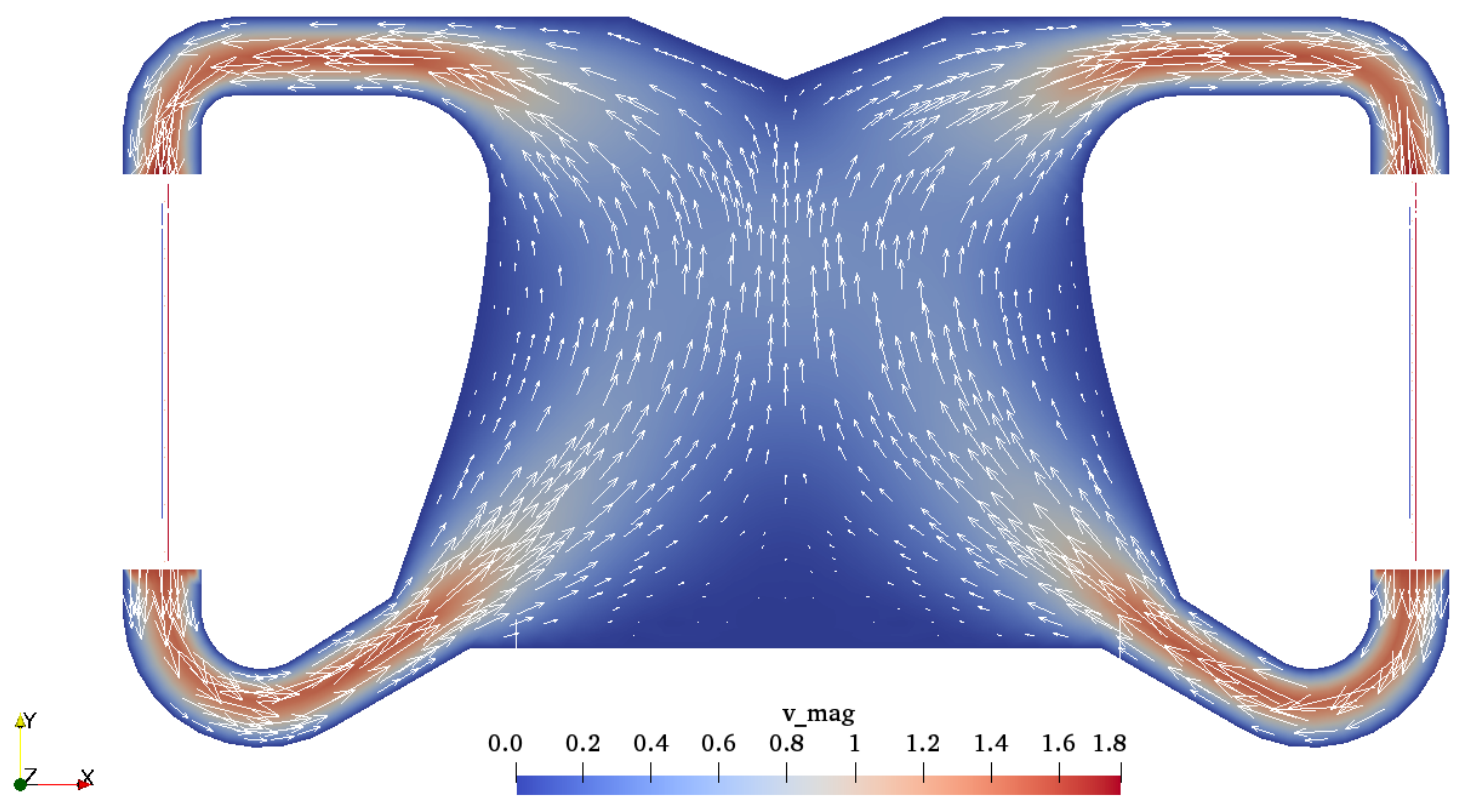

Figure 21. The steady-state velocity field in the MSFR system. 


\section{Conclusions and Future Work}

This report presents results from the second wave of collaboration projects of the center of excellence. The first wave was presented in a previous report [16].

The first project involved Framatome and it analyzed the effect of localized cross-flows on the stability of peripheral LWR Fuel Rods. Four cases of jet flow impinging on axial flow through a bare rod bundle are simulated using LES. The cases are defined by a gap centered, perpendicular jet, a gap centered jet at a 45-degree angle with the flow, a rod centered perpendicular jet, and a rod centered jet at a 45-degree angle with the flow. The perpendicular jets tend to create a stagnation region, resulting in a highly fluctuating transverse velocity field extending $\sim 15 \mathrm{~cm}$ downstream. The jets at 45-degree angles exhibit similar behavior of the jet entraining transverse flow, but with no reverse axial flow. The rod centered jet's influence is much less widespread but results in greater pressure fluctuations on the rods immediately surrounding the jet. The greatest pressure fluctuations are present between the jet inlet and around $10 \mathrm{~cm}$ downstream, peaking somewhere in between. Another peak is observed about $20 \mathrm{~cm}$ downstream from the jet where the low-pressure region ends. The work represents an important stepping stone in the understanding the effect of LOCA holes and it will be extended in future collaborations.

The second project involved TerraPower and the creation of an MSFR demo. The presented work is an important first step to apply state-of-the-art system code in MSFR related applications. A standard SAM problem was developed in this work based on a reference design previously studied under the European EVOL program to assess SAM code capabilities for the primary loop simulations of MSFR. It is noted that the standard problems are foundational to the methodologies employed by the industry user community to verify the adequacy of computer codes and evaluation models. It has been successfully demonstrated that SAM can be used in modeling the complete MSFR primary loop with the multi-D/1-D coupling techniques. A 2-D core is modeled herein, and the extension to a 3-D MSFR is straightforward with the same coupling scheme. Meanwhile, several technical challenges are identified in the process:

1. An efficient yet adequately accurate turbulence modeling capability is desired in SAM. A basic mixing length model was utilized in the current study and the turbulence modeling still involves significant amount of empiricism at the moment. To preserve SAM's excellent efficiency while improving the fluid solution accuracy, novel reduced-order models will be pursued instead of the implementation of traditional turbulence models. The improved accuracy of turbulence modeling will also help better predict the flow recirculation phenomenon inside the core.

2. While the SAM efficiency has been well demonstrated in problems involving OD or 1D components, guidelines of efficient three-dimensional meshing and simulation workflow are to be established.

3. The current $1 \mathrm{D} /$ multi-D coupling strategy still requires improvements. An issue related to two-way data communication in the parallel mode has been recently resolved. However, the current data synchronization scheme still has stability or convergence issues for transient simulations, i.e. the coupled simulation of fast transients could diverge or result in non-physical results.

In light of the challenges listed above, continuous study will focus on addressing these limitations and further expanding SAM's modeling capabilities for MSFR design needs. In addition, transient 
simulations are to be performed to study the MSFR system response under postulated operational or accident scenarios

\section{Acknowledgement}

This work was supported by the U.S. DOE NEAMS program through the Center of Excellence for Thermal Fluids Application in Nuclear Energy. The report has been created by UChicago Argonne, LLC, Operator of Argonne National Laboratory ("Argonne"). Argonne, a U.S. Department of Energy Office of Science laboratory, is operated under Contract No. DE-AC02-06CH11357.

\section{References}

[1] Jacques, Y., Bariber, D., Boulanger, P. Flow induced vibrations for PWR fuel rods under local jets: resonance amplitude in the stability range. In: Transactions of the $14^{\text {th }}$ International Conference on Structural Mechanics in Reactor Technology (SMiRT 14), Paper: J05/2, Lyon, France, August 17-22, 1997.

[2] NRC information available online at https://www.nrc.gov/reactors/operating/opsexperience/baffle-former-bolts.html (January 22, 2020)).

[3] M.P. Païdoussis, S.J. Price, and Emmanuel de Langre. Fluid-structure interactions: crossflow induced instabilities. Cambridge University Press, 2010.

[4] Jacques, Y., Bariber, D., Boulanger, P. Flow induced vibrations for PWR fuel rods under local jets: resonance amplitude in the stability range. In: Transactions of the $14^{\text {th }}$ International Conference on Structural Mechanics in Reactor Technology (SMiRT 14), Paper: J05/2, Lyon, France, August 17-22, 1997.

[5] K. Fujita, T. Ito, and N. Kohno. Experimental study on the vibration of circular cylinders subjected to cross-flow jetted from a narrow gap. Journal of Fluids and Structures, 4(1):99-124, 1990.

[6] K. Fujita. Simulation analysis using cfd on vibration behaviors of circular cylinders subjected to free jets through narrow gaps in the vicinity of walls. WIT Transactions on the Built Environment, 105: 85-95, 2009.

[7] L. Brockmeyer, E. Merzari, J. Solberg, K. Karazis, and Y. Hassan, "High fidelity simulation and validation of crossflow through a tube bundle and the onset of vibration," Int. J. Non. Linear. Mech., vol. 117, July 2019.

[8] Fischer and J. Mullen, "Filter-based stabilization of spectral element methods," Comptes Rendus l'Académie des Sci. - Ser. I - Math., vol. 332, no. 3, pp. 265-270, 2001.

[9] C. Geuzaine and J.-F. Remacle, Gmsh: a three-dimensional finite element mesh generator with built-in pre-and post-processing facilities. International Journal for Numerical Methods in Engineering, Volume 79, Issue 11, pages 1309-1331, 2009

[10] R. Hu, "SAM Theory Manual (No. ANL/NE-17/4),” Argonne National Laboratory, Lemont, IL, 2017. 
[11] H. Rouch et al., "Preliminary thermal-hydraulic core design of the Molten Salt Fast Reactor (MSFR),” Ann. Nucl. Energy, vol. 64, pp. 449-456, 2014.

[12] A. Ribes and C. Caremoli, "Salomé platform component model for numerical simulation," in 31st Annual International Computer Software and Applications Conference (COMPSAC 2007), 2007, vol. 2, pp. 553-564.

[13] R. H. Guymon, "MSRE systems and components performance,” ed. and comp.; Oak Ridge National Lab., Tenn.(USA), 1973.

[14] V. Ariu, "Heat exchanger analysis for innovative molten salt fast reactor," Paul Scherrer Institute, 2014.

[15] S. E. Beall, P. N. Haubenreich, R. B. Lindauer, and J. R. Tallackson, "MSRE Design and Operations Report. Part V. Reactor Safety Analysis Report (No. ORNL-TM-732),” Oak Ridge National Laboratory, Oak Ridge, TN, 1964.

[16] Shaver, Dillon, Rui Hu, Prasad Vegendla, Ling Zou, and Elia Merzari. Initial Industry Collaborations of the Center of Excellence. No. ANL/NSE-19/15. Argonne National Lab. (ANL), Argonne, IL (United States), 2019. 


\section{Argonne}

\section{Nuclear Science and Engineering}

Argonne National Laboratory

9700 South Cass Avenue, Bldg. 208

Argonne, IL 60439

www.anl.gov 